\title{
Chloramphenicol and tetracycline decrease motility and increase invasion and attachment gene expression in specific isolates of multidrug-resistant Salmonella enterica serovar Typhimurium
}

\author{
Brian W. Brunelle ${ }^{1 *}$, Bradley L. Bearson ${ }^{2}$ and Shawn M. D. Bearson ${ }^{1}$ \\ Food Safety and Enteric Pathogens Research Unit, National Animal Disease Center, Agricultural Research Service, United States Department of Agriculture, \\ Ames, IA, USA \\ ${ }^{2}$ Agroecosystems Management Research Unit, National Laboratory for Agriculture and the Environment, Agricultural Research Service, United States Department \\ of Agriculture, Ames, IA, USA
}

\section{Edited by:}

Kunihiko Nishino, Osaka University, Japan

\section{Reviewed by:}

Yuji Morita, Aichi Gakuin University, Japan

Masato Akiba, National Institute of Animal Health, Japan

*Correspondence:

Brian W. Brunelle, Food Safety and Enteric Pathogens Research Unit, National Animal Disease Center, Agricultural Research Service, United States Department of Agriculture, 1920 Dayton Ave., Ames, IA 50010, USA

e-mail: brian.brunelle@ars.usda.gov
Salmonella enterica serovar Typhimurium is one of the most common serovars isolated from humans and livestock, and over 35\% of these isolates are resistant to three or more antibiotics. Multidrug-resistant (MDR) Salmonella is a public health concern as it is associated with increased morbidity in patients compared to antibiotic sensitive strains, though it is unknown how the antibiotic resistant isolates lead to a more severe infection. Cellular invasion is temporally regulated in Salmonella and normally occurs during late-log and stationary growth. However, our previous work determined that a 30 min exposure to a sub-inhibitory concentration of tetracycline can induce the full invasion phenotype during early-log growth in certain MDR $S$. Typhimurium isolates. The current study examined whether sub-inhibitory concentrations of other antibiotics could also induce the invasiveness in the same set of isolates. Ampicillin and streptomycin had no effect on invasion, but certain concentrations of chloramphenicol were found to induce invasion in a subset of isolates. Two of the isolates induced by chloramphenicol were also inducible by tetracycline. RNA-seq analyses demonstrated that chloramphenicol and tetracycline both down-regulated motility gene expression, while up-regulating genes associated with attachment, invasion, and intracellular survival. Eleven fimbrial operons were up-regulated, which is notable as only three fimbrial operons were thought to be inducible in culture; six of these up-regulated operons have been reported to play a role in Salmonella persistence in mice. Overall, these data show that the normal progression of the genetic pathways that regulate invasion can be expedited to occur within 30 min due to antibiotic exposure. This altered invasion process due to antibiotics may play a role in the increased intensity and duration of infection observed in patients with MDR Salmonella.

Keywords: antibiotics, attachment, chloramphenicol, fimbriae, invasion, motility, Salmonella, tetracycline

\section{INTRODUCTION}

Salmonella is a highly prevalent bacterial food-borne disease. Annually in the United States, human salmonellosis is estimated to cause over 1 million cases, 19,000 hospitalizations, 350 deaths, and \$2.6 billion in associated costs (Economic Research Service, 2009; Scallan et al., 2011). Salmonella enterica serovar Typhimurium is one of the most commonly isolated salmonellae in both humans and livestock, and there is a high incidence of antibiotic resistance among these isolates. According to a 10 -year average from the National Antimicrobial Resistance Monitoring System (NARMS), isolates resistant to three or more antibiotics are frequent among $S$. Typhimurium from humans (35\%), chickens $(41 \%)$, cattle $(63 \%)$, and swine $(78 \%)$ (CDC, 2012). The NARMS report also lists that the four most common antibiotics to

Abbreviations: MDR, multidrug-resistant; FDR, false discovery rate; SPI, Salmonella pathogenicity island; TTSS, type three secretion system. which human isolates of $S$. Typhimurium are resistant are tetracycline (33\% of isolates), ampicillin (31\%), streptomycin (31\%), and chloramphenicol $(24 \%)$. Resistance to these antibiotics is mediated by antibiotic-specific mechanisms that can be acquired via horizontal transfer (tetA, floR, strA, etc.). Multidrug-resistant (MDR) Salmonella has emerged as an important food safety concern and is associated with increased morbidity in humans compared to antibiotic sensitive strains (Molbak, 2005; Varma et al., 2005). However, little is known why MDR Salmonella is more virulent as it is not due to an intrinsically higher capacity to invade eukaryotic cells in vitro; in fact, MDR Salmonella has been reported to be less invasive in tissue culture experiments compared to antibiotic-sensitive strains (Carlson et al., 2000). The increased virulence capacity may be triggered by effectors in the environment, the host, or both.

A temporal progression of regulated expression occurs in Salmonella for genes associated with virulence and cellular 
invasion (Ibarra et al., 2010; Saini et al., 2010; Fabrega and Vila, 2013). During early-log growth, Salmonella express flagella and are motile, but have limited-to-no invasive capabilities. As late-log and stationary phases are reached, motility is downregulated, and genes associated with attachment, invasion, and intracellular survival are up-regulated. Attachment is mediated by fimbriae, and $S$. Typhimurium encodes up to 13 fimbrial operons (McClelland et al., 2001). Invasion genes are located in Salmonella Pathogenicity Island 1 (SPI-1), which encodes a type three secretion system (TTSS) and effector molecules that promote cellular entry (Lostroh and Lee, 2001). SPI-2 also encodes a TTSS and effector molecules, but these and the genes expressed in SPI-3 promote Salmonella intracellular survival (Kuhle and Hensel, 2004).

Antibiotics can affect the regulation of cellular processes in bacteria (Goh et al., 2002; Kuroda et al., 2007; Shen et al., 2008; Deneve et al., 2009; Morita et al., 2014). For example, florfenicol can induce adherence of Staphylococcus aureus (Blickwede et al., 2005), and tetracycline can increase TTSS expression and cytotoxicity in Pseudomonas aeruginosa (Linares et al., 2006). However, the majority of bacteria in such studies are resistant to antibiotics due to intrinsic factors (such as mutations) or efflux pumps that work against a suite of antimicrobials. Antibiotic-specific genes often provide a much higher level of resistance compared to the non-specific antimicrobial pumps and can allow growth at an antibiotic concentration that might otherwise be inhibitory to sensitive bacteria. We previously characterized the effect different sub-inhibitory concentrations of the antibiotic tetracycline had on the invasiveness of eight MDR $S$. Typhimurium isolates that encoded tetracycline-specific resistance efflux pumps (Brunelle et al., 2013). We found that a subset of the isolates had an induced invasion phenotype during early-log growth phase in response to $16 \mu \mathrm{g} / \mathrm{ml}$ of tetracycline. The induced invasiveness was not observed with lower concentrations of tetracycline during early-log growth (1 and $4 \mu \mathrm{g} / \mathrm{ml})$, nor did tetracycline enhance invasion in any isolate during late-log growth at any antibiotic concentration tested. The goals of the current study were to establish if ampicillin, chloramphenicol, or streptomycin can also induce invasion in the same isolates, and to assess transcriptional changes for genes associated with the virulence functional groups (motility, SPI-1, SPI-2, SPI-3, and attachment) due to antibiotic exposure.

\section{MATERIALS AND METHODS ISOLATES}

Eight isolates of Salmonella enterica serovar Typhimurium phage types DT104 (530, 290, 360) and DT193 (1434, 5317, 752, 1306, 4584) originally from cattle, and previously tested for differences in invasiveness after exposure to tetracycline (Brunelle et al., 2013), were selected for study. These isolates were cultured on solid media with antibiotic concentrations based on CLSI breakpoints, and it was identified that they are resistant to ampicillin $(32 \mu \mathrm{g} / \mathrm{ml})$, chloramphenicol $(32 \mu \mathrm{g} / \mathrm{ml})$, streptomycin $(64 \mu \mathrm{g} / \mathrm{ml})$, and tetracycline $(16 \mu \mathrm{g} / \mathrm{ml})$, but are sensitive to gentamicin $(16 \mu \mathrm{g} / \mathrm{ml})$.

\section{CHARACTERIZATION OF ANTIBIOTIC RESISTANCE GENES}

Primers (Table 1) were used to amplify and detect the most common resistance genes in Salmonella for the following antibiotics: ampicillin $\left(b l a_{C M Y}, b l a_{O X A}, b l a_{P S E}, b l a_{T E M}\right.$, and bla $\left.a_{S H V}\right)$, chloramphenicol (cat, $\mathrm{cml}$, and floR), and streptomycin (aadA2, strA, and $\operatorname{str} B$ ). Tetracycline resistance genes in these isolates (tet $A$, $B, C, D$, and $G$ ) were characterized previously (Brunelle et al., 2013). DNA was obtained by boiling a single colony from each isolate in $30 \mu \mathrm{l}$ water. Each $25 \mu \mathrm{L}$ PCR reaction contained $1.5 \mu \mathrm{l}$ DNA, 1.5 units of Taq polymerase (Promega), 1x PCR buffer

Table 1 | Primers used for identification and real-time PCR.

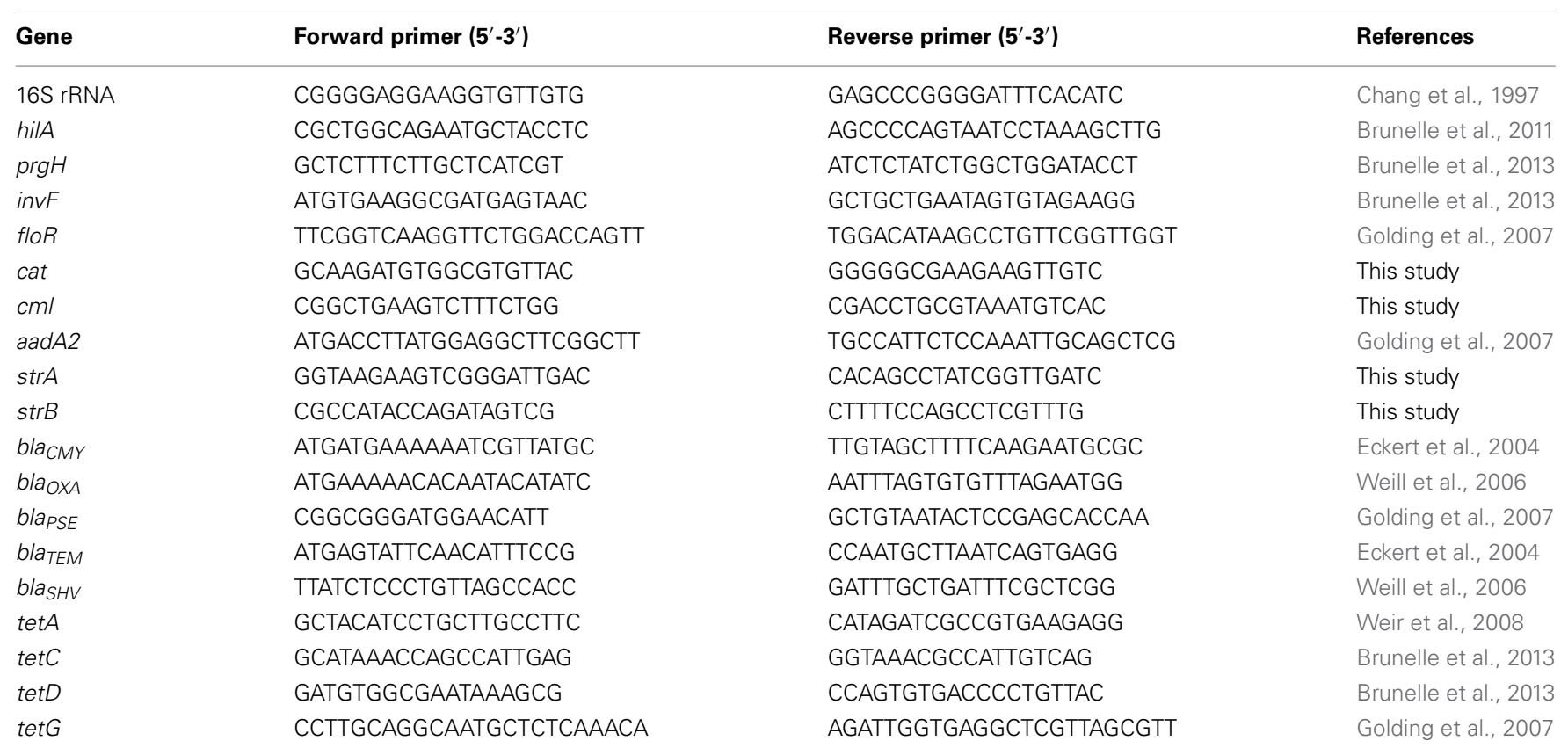


with $1.5 \mathrm{mM} \mathrm{MgCl}_{2}, 1 \mathrm{mM}$ each dNTP, and $0.8 \mu \mathrm{M}$ of each primer. Amplification conditions were: $94^{\circ} \mathrm{C}$ for $1 \mathrm{~min} ; 35$ cycles of $94^{\circ} \mathrm{C}$ for $30 \mathrm{~s}, 56^{\circ} \mathrm{C}$ for $30 \mathrm{~s}, 72^{\circ} \mathrm{C}$ for $30 \mathrm{~s} ; 72^{\circ} \mathrm{C}$ for $2 \mathrm{~min} ; 4^{\circ} \mathrm{C}$ hold. Amplifications were done in duplicate and products were visualized on $2 \%$ NuSieve agarose gels (Cambrex, Rockland, ME).

\section{CHARACTERIZATION OF ANTIBIOTIC CONCENTRATIONS THAT INHIBIT GROWTH}

The antibiotic concentration that inhibited growth in broth culture for each isolate was determined. Overnight cultures were diluted 1:200 in LB and grown to early-log phase $\left(\mathrm{OD}_{600}=0.15\right)$ at $37^{\circ} \mathrm{C}$ with agitation before adding serial 2-fold dilutions of ampicillin, chloramphenicol, or streptomycin $(0,2-512 \mu \mathrm{g} / \mathrm{ml})$. All conditions were done in triplicate. Cultures were continuously shaken at $37^{\circ} \mathrm{C}$, and growth measurements $\left(\mathrm{OD}_{600}\right)$ were taken every hour for $24 \mathrm{~h}$ using a Bioscreen $\mathrm{C}$ instrument (Growth Curves LTD, Raisio, Finland). Growth curves on serial dilutions of tetracycline were established previously (Brunelle et al., 2013).

\section{CULTURE CONDITIONS}

For each experiment, Salmonella was plated on Lennox L (LB) agar plates (Invitrogen, Carlsbad, CA), and a single colony was selected and grown in LB broth with agitation for $6 \mathrm{~h}$ at $37^{\circ} \mathrm{C}$. The $6 \mathrm{~h}$ culture was diluted 1:1000 in fresh LB broth and grown with agitation at $37^{\circ} \mathrm{C}$ overnight. The overnight culture was diluted 1:200 in fresh LB broth and divided into $16 \times 100 \mathrm{~mm}$ glass tubes. Cultures were grown to early-log $\left(\mathrm{OD}_{600}=0.15\right)$ with agitation at $37^{\circ} \mathrm{C}$ before antibiotic addition. An aliquot was taken for RNA analysis from each culture and placed in RNAProtect (QIAGEN, Germantown, MD). Ampicillin, chloramphenicol, and streptomycin were added to separate tubes for a final concentration of 0 (control), 16, 32, 64, and $128 \mu \mathrm{g} / \mathrm{ml}$, and these were incubated with agitation at $37^{\circ} \mathrm{C}$ for $30 \mathrm{~min}$; tetracycline was assayed at only 0 and $16 \mu \mathrm{g} / \mathrm{ml}$. Aliquots for RNA analysis were taken from each bacterial culture and placed in RNAProtect. An additional aliquot was taken from each culture for a cell culture invasion assay. All experiments were performed four separate times.

\section{SALMONELLA INVASION ASSAYS}

The aliquots of Salmonella cultures taken following the $30 \mathrm{~min}$ incubation with and without antibiotics were centrifuged at $16,000 \times \mathrm{g}$ for $2 \mathrm{~min}$, and the pellets were re-suspended in fresh $\mathrm{LB}$ broth to remove the antibiotic. Invasion assays were performed with technical replicates for each biological replicate using a gentamicin protection assay in HEp-2 cells at a multiplicity of infection of $\sim 40$ as previously described (Elsinghorst, 1994). Percent invasion was calculated by dividing the $\mathrm{CFU} / \mathrm{ml}$ recovered by the CFU/ml originally added to the cells. The significance of the differences in invasion was determined by a one-way repeated measures ANOVA with Dunnett's post-test to assess pair-wise differences between the no-antibiotic control and the other sample conditions using GraphPad Prism 5 (San Diego, CA). Differences were considered significant if $P<0.05$. Each isolate has an intrinsically different invasion rate when grown without antibiotics; therefore the invasion data for each isolate was normalized to its respective control for graphical representation.

\section{REAL-TIME PCR ASSAYS}

RNA was isolated using the RNeasy Mini Kit (QIAGEN, Germantown, MD), and genomic DNA was removed by the Turbo DNase DNA-free kit (Ambion, Austin, TX) according to the product directions. Total RNA was quantitated on a Nanodrop ND-1000 spectrophotometer (Thermo Scientific, Wilmington, DE). Reverse transcription was carried out by the Applied Biosystems High capacity cDNA reverse transcription kit on total RNA with random primers (Life Technologies, Grand Island, NY), and two technical replicates were performed for each of the three biological replicates. Real-Time PCR was performed in a Bio-Rad CFX96 Real-Time PCR Detection System (BioRad Laboratories, Hercules, CA) using the SYBR Green Master Mix (Applied Biosystems, Foster City, CA). Primer sets were used to evaluate the 16S rRNA, hilA, floR, tet $A$, tet $C$, tetD, and tet $G$ transcripts (Table 1). For control assays, reverse transcriptase was not added to parallel mixtures for each sample. The amplification cycle conditions were as follows: $95^{\circ} \mathrm{C}$ for $10 \mathrm{~min} ; 40$ cycles of $95^{\circ} \mathrm{C}$ for $15 \mathrm{~s}, 55^{\circ} \mathrm{C}$ for $30 \mathrm{~s}, 72^{\circ} \mathrm{C}$ for $30 \mathrm{~s}$; melting curve analysis from $65^{\circ} \mathrm{C}$ to $95^{\circ} \mathrm{C}$. Raw fluorescence data was analyzed with the LinRegPCR software, and amplification efficiencies and cycle threshold $\left(\mathrm{C}_{\mathrm{T}}\right)$ values were determined by linear regression in a Window of Linearity for each primer set (Ramakers et al., 2003). Expression differences were calculated using the $\mathrm{C}_{\mathrm{T}}$ value and efficiency for each locus by the Pfaffl method (Pfaffl, 2001), where the $16 \mathrm{~S}$ gene was the reference gene and the pre-antibiotic sample was the control condition for each isolate at each antibiotic concentration. Values were $\log _{2}$ transformed, and GraphPad Prism 5 was used to perform a one-way repeated measures ANOVA with Dunnett's post-test to assess pair-wise differences between the noantibiotic control and the other sample conditions. Differences were considered significant if $P<0.05$.

\section{RNA TRANSCRIPTOME SEQUENCING}

Isolates $1434,5317,752,4584$, and 530 were selected for RNAseq analysis to identify changes in virulence gene expression due to tetracycline $(0$ and $16 \mu \mathrm{g} / \mathrm{ml})$ and chloramphenicol $(0,32$, and $64 \mu \mathrm{g} / \mathrm{ml}$ ) exposure. RNA from three biological replicates of each isolate and condition were used for sequencing. Quality and integrity of the RNA was assessed with the 2100 Bioanalyzer (Agilent Technologies, Santa Clara, CA). The RiboZero kit was used to deplete the ribosomal RNA (rRNA) sequences according to the manufacturer's instructions (Epicentre, Madison, WI). The 2100 Bioanalyzer was used to verify removal of the rRNA. Libraries were constructed using TruSeq RNA Sample prep kit and were sequenced on a HiSeq 2500 employing a 100-cycle run (Illumina Inc., San Diego, CA) at the Iowa State University DNA core facility.

\section{RNA-SEO DATA ANALYSES}

CLC Genomics Workbench v7.0 was used to import the Illumina sequence data. Failed reads were removed prior to analysis. The $S$. Typhimurium SL1344 genome [GenBank: FQ312003] and three plasmids [GenBank: HE654724-26], as well as a MDR plasmid from S. Heidelberg [GenBank JN983048], were used as references for mapping with the following parameters: 2 maximum mismatches, $90 \%$ minimum length fraction, $80 \%$ minimum 
similarity fraction, and 10 maximum hits per read. Differences in gene expression were calculated using EdgeR (total count filter cut-off $=5.0)$ with False Discovery Rate (FDR) corrected $P$-values (Robinson et al., 2010). Differences were considered significant if $P<0.05$. Fold-changes for RNA-seq data described in the study are the weighted differences between groups based on counts per million calculated in EdgeR. Functional categories for genes associated with motility, attachment, SPI-1, SPI-2, and SPI-3 were manually assigned.

\section{ELECTRON MICROSCOPY}

Salmonella isolate 1434 was grown in LB to early-log growth phase followed by a $30 \mathrm{~min}$ antibiotic exposure to $64 \mu \mathrm{g} / \mathrm{ml}$ chloramphenicol, $16 \mu \mathrm{g} / \mathrm{ml}$ tetracycline, or no antibiotic (control) as described above. One $\mathrm{ml}$ of each culture was centrifuged at 1000 $\times \mathrm{g}$ for $5 \mathrm{~min}$, the supernatant was removed, and the pellet was re-suspended in $0.5 \mathrm{ml}$ of $0.5 \%$ methyl cellulose solution in water (Mitani and Iino, 1968). Samples were prepared for negative stain examination by electron microscopy following previously described procedures (Doane and Anderson, 1987). Each sample was negatively stained with $2 \%$ phosphotungstic acid $(\mathrm{pH} 7.0)$ and examined with a FEI Tecnai $\mathrm{G}^{2}$ BioTWIN electron microscope (FEI Co., Hillsboro, OR) at the National Animal Disease Center Core Facility.

\section{RESULTS AND DISCUSSION}

Our previous work investigated eight MDR $S$. Typhimurium isolates that were resistant to ampicillin, chloramphenicol, streptomycin, and tetracycline and demonstrated that a sub-inhibitory concentration of tetracycline induced the full invasive phenotype in a subset of these isolates during early-log growth phase
(Brunelle et al., 2013). In order to determine if other antibiotics could induce invasiveness in the same eight isolates, the current study used invasion assays to test their response to subinhibitory concentrations of ampicillin, chloramphenicol, and streptomycin. Real-time PCR and RNA-seq were used to assess expression changes of genes associated with antibiotic resistance, as well as with the temporal regulation of the invasion phenotype.

\section{CHARACTERIZATION OF ANTIBIOTIC RESISTANCE}

PCR was used to identify the presence of commonly encoded MDR Salmonella genes that mediate resistance to ampicillin $\left(b l a_{C M Y}, b l a_{O X A}, b l a_{P S E}, b l a_{T E M}\right.$, and $\left.b l a_{S H V}\right)$, chloramphenicol (cat, $\mathrm{cml}$, and floR), and streptomycin ( $\operatorname{aad} A 2, \operatorname{str} A$, and $\operatorname{str} B$ ). With the exception of $b l a_{T E M}$ and $b l a_{O X A}$, all genes were present in some combination in the eight isolates (Table 2). The tetracycline resistance genes in these isolates were established previously (Brunelle et al., 2013). As expected, bla $a_{P S E}$, aadA2, and tet $G$ were identified in all three DT104 isolates, but not in any of the DT193 isolates, as these resistance genes are typically chromosomally encoded on the Salmonella Genomic Island 1 (SGI-1) in DT104 (Boyd et al., 2001). Of note is that 4584 was the only isolate to lack the floR gene, as well as the only one to encode the cat gene.

The effect different concentrations $(0,2-512 \mu \mathrm{g} / \mathrm{ml})$ of ampicillin, chloramphenicol, and streptomycin had on the growth of each isolate was determined (Table 2). For chloramphenicol, growth was inhibited at $128 \mu \mathrm{g} / \mathrm{ml}$ for six of the isolates, including isolate 1434 (Figure 1), and at $256 \mu \mathrm{g} / \mathrm{ml}$ for isolate 360 (Table 2). Isolate 4584 grew at $512 \mu \mathrm{g} / \mathrm{ml}$, which is likely because it encodes the antibiotic-modifying enzyme chloramphenicol acetyltransferase (cat) instead of the efflux pumps floR or $\mathrm{cml}$ (Schwarz

Table 2 | Resistance gene profiles for the eight $S$. Typhimurium isolates in the study.

\begin{tabular}{|c|c|c|c|c|c|c|c|c|c|c|}
\hline \multirow[t]{2}{*}{ Isolate } & \multicolumn{6}{|c|}{ Tetracycline } & \multicolumn{4}{|c|}{ Chloramphenicol } \\
\hline & tetA & tetB & tetC & tetD & tetG & $\mathrm{MIC} \mu \mathrm{g} / \mathrm{ml}$ & floR & cat & $\mathrm{cml}$ & $\mathrm{MIC} \mu \mathrm{g} / \mathrm{ml}$ \\
\hline 1434 & + & - & - & - & - & 256 & + & - & - & 128 \\
\hline 5317 & + & - & - & - & - & 256 & + & - & + & 128 \\
\hline 752 & + & - & - & - & - & 256 & + & - & - & 128 \\
\hline 1306 & + & + & + & + & - & 256 & + & - & + & 128 \\
\hline 4584 & - & + & + & + & - & 256 & - & + & - & $>512$ \\
\hline 530 & - & - & - & - & + & 64 & + & - & - & 128 \\
\hline 290 & - & - & - & - & + & 64 & + & - & - & 128 \\
\hline 360 & - & - & - & - & + & 64 & + & - & - & 256 \\
\hline \multirow[t]{2}{*}{ Isolate } & \multicolumn{6}{|c|}{ Ampicillin } & \multicolumn{4}{|c|}{ Streptomycin } \\
\hline & $C M Y$ & PSE & SHV & $O X A$ & TEM & MIC $\mu \mathrm{g} / \mathrm{ml}$ & aadA2 & strA & strB & MIC $\mu \mathrm{g} / \mathrm{ml}$ \\
\hline 1434 & + & - & + & - & - & $>512$ & - & + & + & $>512$ \\
\hline 5317 & + & - & + & - & - & $>512$ & - & + & + & $>512$ \\
\hline 752 & + & - & + & - & - & $>512$ & - & + & + & $>512$ \\
\hline 1306 & - & - & + & - & - & $>512$ & - & + & + & $>512$ \\
\hline 4584 & - & - & + & - & - & $>512$ & - & + & + & $>512$ \\
\hline 530 & - & + & + & - & - & $>512$ & + & - & - & $>512$ \\
\hline 290 & - & + & + & - & - & $>512$ & + & - & - & $>512$ \\
\hline 360 & - & + & + & - & - & $>512$ & + & - & - & $>512$ \\
\hline
\end{tabular}




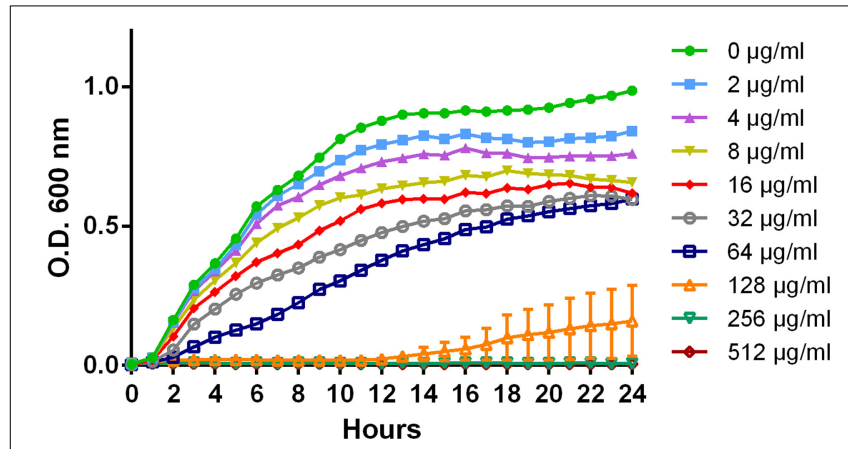

FIGURE 1 | Growth curve of multidrug-resistant S. Typhimurium isolate 1434 exposed to chloramphenicol. Serial two-fold dilutions of chloramphenicol $(0,2-512 \mu \mathrm{g} / \mathrm{ml})$ were added at $\mathrm{OD}_{600}=0.15$ to the eight isolates in the study to assess the effect chloramphenicol exposure had on growth. The growth curve of isolate 1434 is representative of the other isolates, with the exception of 4584 .

et al., 2004). The ampicillin and streptomycin resistance genes in the isolates encode modifying enzymes, and neither antibiotic inhibited growth at any of the concentrations that were tested.

\section{CHLORAMPHENICOL INDUCES INVASION IN THREE ISOLATES}

Based on the growth data, 0, 16, 32, 64, and $128 \mu \mathrm{g} / \mathrm{ml}$ of ampicillin, chloramphenicol, and streptomycin were chosen as the sub-inhibitory concentrations to test the effect each antibiotic had on invasion during early-log growth phase of the eight isolates. Chloramphenicol induced a significant increase in invasiveness at 32 or $64 \mu \mathrm{g} / \mathrm{ml}$ compared to the no-antibiotic control for three DT193 isolates (1434, 5317, and 1306; Figure 2). The chloramphenicol-induced invasion rates during early-log are similar to the maximum natural invasion rates for each isolate during late-log, which parallels the results observed for tetracycline (Brunelle et al., 2013) (data not shown). Isolates 1434 and 5317 were previously shown to have the invasion phenotype induced after exposure to $16 \mu \mathrm{g} / \mathrm{ml}$ tetracycline for $30 \mathrm{~min}$ during early-log growth. Several isolates had a significant decrease in cellular invasion at $64 \mu \mathrm{g} / \mathrm{ml}(752$ and 530) and $128 \mu \mathrm{g} / \mathrm{ml}(752$, 530, and 360) of chloramphenicol. Neither ampicillin nor streptomycin had an effect on the invasiveness of any of the isolates at any concentration tested (data not shown). Therefore, invasion was induced by two different antibiotics in a subset of isolates that utilize efflux pump-mediated resistance (floR and tet $A$ ), but not in the isolates that use enzyme-mediated resistance (cat, all ampicillin and streptomycin genes). However, several isolates that utilize TetA, TetG, or FloR efflux pumps did not have the induced invasion phenotype.

\section{REAL-TIME PCR ANALYSES}

Real-time PCR was used to assess expression changes of hilA, floR, and the tet genes in all the isolates in response to the $30 \mathrm{~min}$ chloramphenicol exposure.

\section{Differential expression of the hilA gene}

The HilA protein is the master regulator of SPI-1, and increases or decreases in expression of the hilA gene typically have a corresponding increase or decrease on invasion (Lee et al., 1992).

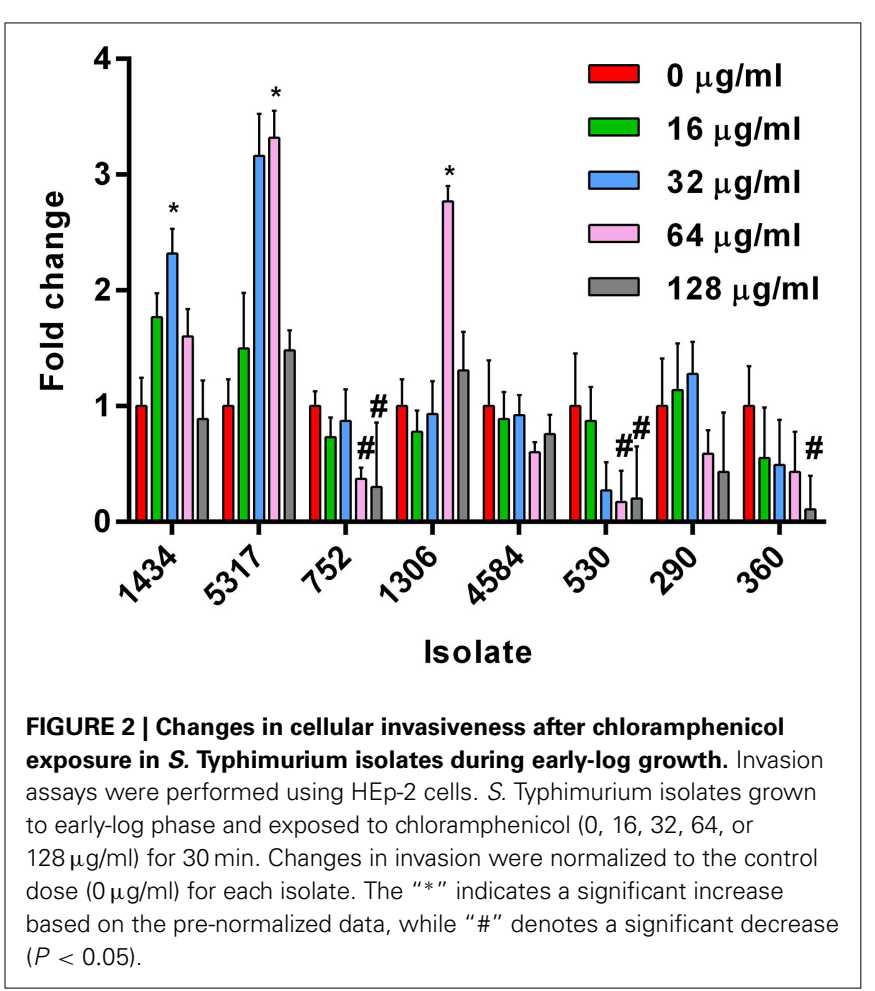

However, increases in hilA expression due to chloramphenicol (Figure 3A) did not always correlate with increased invasiveness (Figure 2); this is highlighted in isolate 530 as 16, 32, and $64 \mu \mathrm{g} / \mathrm{ml}$ of chloramphenicol significantly increased hilA expression without any corresponding changes on invasion. This lack of congruence between increased hilA gene expression and increased invasiveness was previously observed when the isolates were exposed to tetracycline (Brunelle et al., 2013). No changes in hilA expression were detected due to either ampicillin or streptomycin exposure in any of the isolates, which is consistent with the invasion data (data not shown).

\section{Differential expression of the floR gene}

An increase in the expression of floR was significant at all concentrations of chloramphenicol in the seven isolates encoding the gene (Figure 3B). These data indicate that there is no direct association between the up-regulation of floR and the induced invasiveness in isolates 1434,5317 , and 1306 . Therefore, floR may be necessary, but is not sufficient for the observed effect. This parallels previous findings that the increased expression of tet genes due to tetracycline exposure was not directly responsible for tetracycline-induced invasion (Brunelle et al., 2013).

\section{Differential expression of the tetA,C,D,G genes}

Expression changes of the tetracycline resistance genes tet $A$, tet $C$, tet $D$, and tet $G$ were also analyzed in response to chloramphenicol (Figure 3C); tetB expression with or without antibiotic exposure was undetectable, and therefore was not included in the figure. Interestingly, tet $A, C, D$, and $G$ were found to be up-regulated due to exposure to various concentrations of chloramphenicol (and 


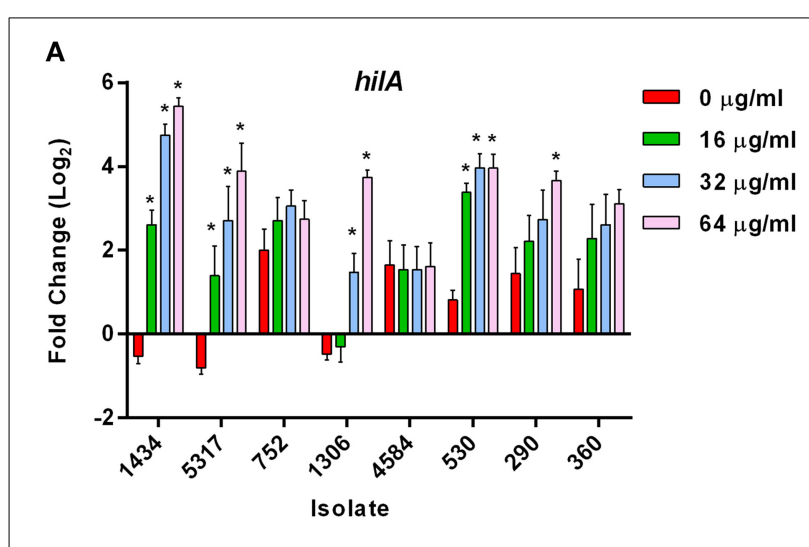

B
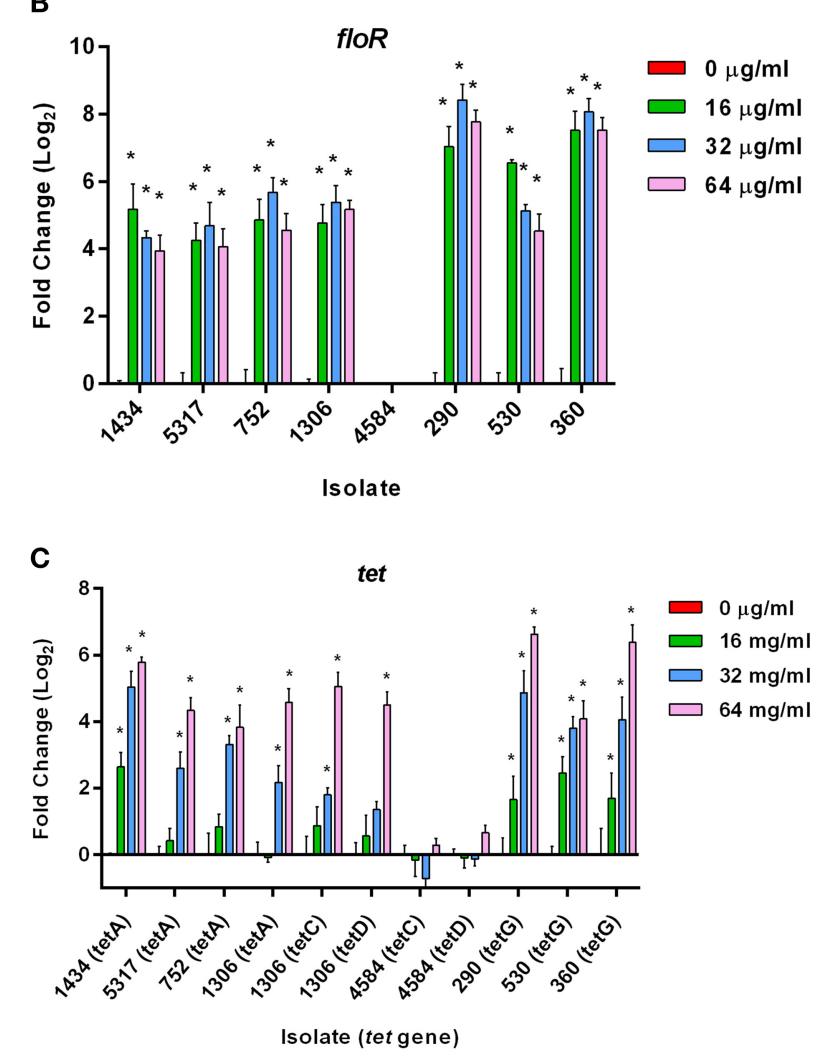

FIGURE 3 | Gene expression changes in S. Typhimurium at early-log growth after chloramphenicol exposure. Real-time gene expression assays were performed on eight MDR S. Typhimurium isolates grown to early-log phase and exposed to different concentrations of chloramphenicol $(0,16,32$, and $64 \mu \mathrm{g} / \mathrm{ml})$ for $30 \mathrm{~min}$. The "** denotes a significant change in expression over the $30 \mathrm{~min}$ compared to the control (pre-incubation) $(P<0.05)$. (A) Gene expression changes in the hilA gene. (B) Gene expression changes in the chloramphenicol-resistance flo $R$ gene (not present in isolate 4584). (C) Gene expression differences in the tetracycline-resistance genes in the eight isolates due to chloramphenicol exposure.

in the absence of tetracycline) in most of the isolates. Only isolate 4584, which encodes tet $C$, tet $D$, and cat but lacks tet $A$ and floR, did not have a change in expression of its tet genes. In contrast, the tet $C$ and tet $D$ genes in isolate 1306 were up-regulated at
$64 \mu \mathrm{g} / \mathrm{ml}$ of chloramphenicol. Isolate 1306 encodes both floR and tet $A$, and it may be the presence of one or both of these two genes that is needed to co-regulate tet $C$ and tet $D$ expression after exposure to chloramphenicol. Additionally, floR is frequently adjacent to tet $A$ in DT193 and tetG in DT104. Although these genes are in opposite orientations and would not be in the same operon, it could be the proximity of these genes that allows chloramphenicol to induce the tet genes independently of tetracycline. PCR confirmed the order and orientation of the floR and tet $A / G$ genes in the isolates.

\section{RNA-SEO IDENTIFIES DIFFERENTIAL REGULATION OF THE VIRULENCE-ASSOCIATED FUNCTIONAL GROUPS DUE TO ANTIBIOTIC EXPOSURE}

In order to assess if the early induction of the full invasive phenotype by chloramphenicol and tetracycline coincided with an acceleration of the temporally regulated virulence pathways, RNA-seq was used to evaluate differences in the expression of genes in the functional groups required for invasion. Five isolates were chosen to study: isolates 1434 and 5317 because they both have an increase in invasion after exposure to tetracycline and chloramphenicol, and both encode floR and tet $A$; isolates 752 and 530 because they do not have increased invasiveness due to antibiotic exposure, but encode floR and either tet $A$ (752) or tet $G$ (530); and isolate 4584 as it did not have a change in its invasion phenotype and lacks floR, tet $A$, and tet $G$. Genes associated with motility, invasion (SPI-1), intracellular survival (SPI-2 and SPI-3), and attachment were examined in isolates exposed separately to no antibiotic (control), $16 \mu \mathrm{g} / \mathrm{ml}$ of tetracycline, and 32 and $64 \mu \mathrm{g} / \mathrm{ml}$ of chloramphenicol for $30 \mathrm{~min}$ during early-log growth. The results for the samples exposed to 32 and $64 \mu \mathrm{g} / \mathrm{ml}$ of chloramphenicol were highly similar, so only the $64 \mu \mathrm{g} / \mathrm{ml}$ of chloramphenicol data are presented. Except for SPI-3, the data for isolate 4584 is not included below as there were no significant changes in any of the genes among the other functional groups.

\section{Motility}

Fifty-four genes associated with motility were assessed, and the majority of these were found to be down-regulated in isolates $1434,5317,752$, and 530 when exposed to chloramphenicol and tetracycline (Figure 4, Table 3). This is highlighted by the flgA-J and $f l i E-N$ genes that encode proteins for the basal body, flagellar hook, and flagellar motor switch. The $10 \mathrm{flg}$ and the 10 fli genes are all significantly down-regulated an average of 18.5fold and 12.8-fold, respectively, in each of the four isolates in response to both antibiotics. The genes that encoded the master regulators of motility, flh $C D$, were not differentially regulated except in isolate 752 where their expression increased due to chloramphenicol. However, the fliA gene that encodes a $\sigma^{28}$ factor and controls regulation of the late-flagellar genes (Chilcott and Hughes, 2000) was significantly down-regulated in most of the samples (the exception was isolate 5317 exposed to chloramphenicol that was down-regulated, but had a $P=0.054)$. Motility genes are typically up-regulated during early-log growth, and are then down-regulated during the mid- to late-growth phase as the invasion genes are up-regulated (Saini et al., 2010). In this study, we observed that tetracycline and chloramphenicol 


\begin{tabular}{|c|c|c|c|c|c|c|c|c|c|c|c|c|c|c|c|c|c|}
\hline \multirow[b]{2}{*}{ Gene } & \multicolumn{4}{|c|}{ Tetracycline } & \multicolumn{4}{|c|}{ Chloramphenicol } & \multirow[b]{2}{*}{ Gene } & \multicolumn{4}{|c|}{ Tetracycline } & \multicolumn{4}{|c|}{ Chloramphenicol } \\
\hline & 1434 & 5317 & 752 & 530 & 1434 & 5317 & 752 & 530 & & 1434 & 5317 & 752 & 530 & 1434 & 5317 & 752 & 530 \\
\hline$a e r$ & -1.6 & -1.5 & -2.0 & 1.0 & -1.5 & 1.2 & 1.5 & -2.3 & fliA & -6.7 & -6.1 & -4.4 & -2.2 & -5.6 & -3.1 & -3.0 & -8.5 \\
\hline cheA & -1.1 & 1.1 & 1.1 & 2.5 & 1.1 & 1.6 & 1.5 & -1.4 & $f l i B$ & -5.8 & -5.0 & -6.0 & -4.6 & -5.4 & -4.9 & -7.7 & -5.3 \\
\hline cheB & -5.1 & -4.1 & -4.3 & -2.0 & -4.9 & -2.7 & -3.6 & -6.5 & flic & -3.6 & -8.6 & -1.2 & 1.1 & -4.1 & -2.0 & 1.5 & -3.2 \\
\hline cheM & -1.4 & -1.6 & -2.1 & 1.5 & -1.2 & 2.0 & 1.6 & -1.2 & fliD & -3.7 & -4.3 & -3.9 & -2.6 & -3.5 & -3.0 & -2.2 & -4.2 \\
\hline cheR & -2.1 & -2.0 & -1.7 & -1.5 & -1.3 & -1.4 & -1.1 & -2.3 & fliE & -13.7 & -10.1 & -11.6 & -11.2 & -13.7 & -16.4 & -13.1 & -20.1 \\
\hline cheW & -1.9 & -1.9 & -2.1 & 1.4 & -2.3 & -1.4 & -1.5 & -1.9 & fliF & -10.6 & -11.0 & -8.4 & -9.2 & -14.7 & -11.1 & -7.2 & -13.6 \\
\hline cheY & -8.8 & -8.0 & -8.4 & -4.1 & -9.0 & -5.1 & -5.9 & -9.3 & fliG & -14.8 & -17.8 & -12.6 & -15.4 & -20.8 & -13.7 & -11.8 & -13.3 \\
\hline cheZ & -8.1 & -5.8 & -7.3 & -3.7 & -7.5 & -4.6 & -5.1 & -7.3 & $\mathrm{fliH}$ & -14.1 & -15.2 & -11.3 & -10.7 & -16.5 & -11.3 & -8.9 & -13.3 \\
\hline$f \lg A$ & -22.6 & -19.2 & -16.6 & -13.4 & -29.9 & -18.8 & -20.0 & -16.7 & flil & -9.3 & -9.2 & -7.3 & -9.1 & -9.8 & -8.4 & -6.4 & -9.7 \\
\hline$f l g B$ & -24.3 & -29.7 & -17.7 & -14.1 & -31.5 & -23.4 & -14.6 & -22.3 & fliJ & -19.9 & -22.3 & -16.5 & -19.5 & -24.4 & -20.5 & -21.1 & -13.6 \\
\hline$f l g C$ & 20.3 & -21.6 & & -11.8 & -20.0 & & -11.7 & -16.1 & flik & -13.2 & -10.5 & & -14.5 & & & -7.8 & -7.9 \\
\hline$f l g D$ & -22.1 & -21.3 & -21.6 & -13.1 & -19.2 & -14.9 & -15.5 & -28.8 & fliL & -12.3 & -11.9 & -13.3 & -13.4 & -16.6 & -12.1 & -14.7 & -14.8 \\
\hline$f l g E$ & -28.6 & -29.8 & -25.8 & -18.9 & -27.0 & -23.8 & -18.9 & -17.4 & fliM & -14.6 & -16.9 & -14.6 & -17.4 & -18.7 & -13.9 & -13.4 & -18.3 \\
\hline$f l g F$ & -17.0 & -16.8 & -17.1 & -12.1 & -17.2 & -15.4 & -12.7 & -13.5 & fliN & -15.2 & -13.8 & -15.8 & -16.2 & -12.1 & -11.5 & -9.0 & -12.9 \\
\hline$f l g G$ & -32.3 & -33.0 & -23.9 & -20.2 & -27.6 & -24.2 & -14.7 & -17.6 & flio & -5.4 & -5.6 & -5.6 & -9.6 & -4.5 & -6.6 & -6.1 & -6.4 \\
\hline $\mathrm{flgH}$ & -18.8 & -18.1 & -19.4 & -10.8 & -18.5 & -14.3 & -13.0 & -22.5 & fliP & -1.8 & -2.1 & -2.7 & -4.4 & -1.5 & -2.7 & -3.4 & -3.6 \\
\hline flgl & -21.2 & -15.1 & -14.4 & -11.0 & -14.4 & -12.2 & -10.2 & -17.7 & $f l i Q$ & 1.1 & -1.1 & -1.6 & -2.6 & 1.4 & -1.6 & -3.2 & -1.4 \\
\hline flg J & -16.3 & -12.6 & -13.9 & -9.4 & -14.7 & -11.6 & -9.9 & -12.2 & fliR & 3.8 & 3.3 & 2.1 & 1.3 & 6.4 & 3.3 & 1.2 & 2.4 \\
\hline flgK & -3.1 & -3.1 & -2.8 & -1.5 & -1.8 & -1.4 & -1.0 & -2.3 & flis & -4.1 & -4.6 & -3.6 & -2.7 & -4.2 & -3.7 & -2.6 & -5.5 \\
\hline$f l g L$ & -3.5 & -3.6 & -3.5 & -1.8 & -2.8 & -1.9 & -1.7 & -2.6 & fliT & -3.9 & -3.6 & -3.3 & -2.6 & -3.6 & -3.1 & -2.4 & -5.1 \\
\hline$f l g M$ & -5.9 & -5.9 & -5.4 & -3.0 & -5.8 & -4.0 & -3.8 & -3.9 & fliY & -5.5 & -4.5 & -5.3 & -3.7 & -4.2 & -4.5 & -4.2 & -4.4 \\
\hline$f l g N$ & -5.1 & -4.8 & -4.2 & -2.4 & -4.3 & -3.1 & -3.4 & -3.9 & fliz & -9.0 & -8.9 & -8.1 & -4.1 & -8.3 & -5.9 & -5.1 & -10.6 \\
\hline flhA & -5.0 & -4.1 & -4.3 & -4.4 & -4.1 & -3.9 & -4.2 & -4.8 & $f l j A$ & -4.6 & -1.2 & -4.3 & -1.8 & -2.6 & 1.1 & -2.0 & -4.0 \\
\hline$f l h B$ & -2.1 & -2.0 & -1.8 & -2.3 & -2.2 & -2.2 & -2.7 & -2.8 & hin & 3.0 & 2.8 & 2.8 & 2.9 & 3.1 & 2.6 & 1.4 & 2.4 \\
\hline$f I h C$ & 1.3 & -1.1 & 1.1 & 1.4 & 1.3 & 2.2 & 3.2 & 1.1 & $\operatorname{mot} A$ & -1.3 & -1.2 & -1.1 & 1.6 & 1.2 & 1.6 & 2.2 & -1.2 \\
\hline$f l h D$ & 1.3 & -1.2 & 1.0 & 1.4 & 1.2 & 2.2 & 3.3 & 1.2 & motB & 1.3 & 1.3 & 1.4 & 2.2 & 1.7 & 2.0 & 2.8 & 1.2 \\
\hline flhE & -9.7 & -8.1 & -6.7 & -7.2 & -8.6 & -5.7 & -7.7 & -5.9 & tar & -1.7 & -1.7 & -1.5 & -1.4 & -1.2 & -1.6 & -1.3 & -1.2 \\
\hline
\end{tabular}

FIGURE 4 | RNA-seq analysis of genes associated with motility. RNA-seq identified the fold-change in expression of genes associated with motility due to exposure to the antibiotics tetracycline $(16 \mu \mathrm{g} / \mathrm{ml})$ or chloramphenicol $(64 \mu \mathrm{g} / \mathrm{ml})$ when compared to the no-antibiotic control. Numbers in bold are significantly different (FDR-adjusted $P<0.05$ ), while numbers in purple italics are not significant. Green denotes increased gene expression, and red indicates decreased gene expression; the intensity of the color highlights greater change.

Table 3 | Mean and Standard Error of the Mean of all gene expression differences within each functional group after antibiotic exposure for

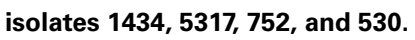

1434

5317

752

530

\section{TETRACYCLINE}

\begin{tabular}{|c|c|c|c|c|}
\hline Motility & $-8.73 \pm 1.15$ & $-8.60 \pm 1.16$ & $-7.58 \pm 0.97$ & $-6.09 \pm 0.89$ \\
\hline SPI-1 & $10.21 \pm 1.05$ & $9.00 \pm 1.25$ & $2.47 \pm 0.59$ & $2.53 \pm 0.40$ \\
\hline SPI-2 & $13.82 \pm 4.07$ & $12.30 \pm 2.96$ & $7.39 \pm 1.50$ & $7.80 \pm 1.55$ \\
\hline SPI-3 & $24.17 \pm 15.75$ & $21.91 \pm 12.92$ & $18.93 \pm 11.98$ & $39.82 \pm 27.93$ \\
\hline Attachment & $10.40 \pm 2.07$ & $10.44 \pm 2.10$ & $8.03 \pm 1.37$ & $5.43 \pm 0.74$ \\
\hline \multicolumn{5}{|c|}{ CHLORAMPHENICOL } \\
\hline Motility & $-8.66 \pm 1.25$ & $-6.80 \pm 1.02$ & $-5.92 \pm 0.86$ & $-8.09 \pm 0.99$ \\
\hline SPI-1 & $10.37 \pm 1.38$ & $8.35 \pm 0.95$ & $1.62 \pm 0.62$ & $3.89 \pm 0.60$ \\
\hline SPI-2 & $11.99 \pm 2.29$ & $10.36 \pm 1.87$ & $5.19 \pm 1.08$ & $4.84 \pm 0.95$ \\
\hline SPI-3 & $22.82 \pm 14.18$ & $23.80 \pm 16.86$ & $30.39 \pm 24.22$ & $23.61 \pm 17.05$ \\
\hline Attachment & $11.33 \pm 1.53$ & $8.55 \pm 1.06$ & $5.97 \pm 0.95$ & $8.07 \pm 1.33$ \\
\hline
\end{tabular}

down-regulate the motility genes in Salmonella during early-log growth.

\section{SPI-1}

Thirty-seven SPI-1 genes related to invasion were examined, which included those genes for SPI-1 regulation (hil), type-three secretion apparatus (sip, spa), and effector molecules (inv, prg)
(Figure 5). While many of the SPI-1 genes are up-regulated in the four isolates, there is a striking difference between the two isolates associated with the induced invasion phenotype (1434 and 5317) and the other two isolates (752 and 530) (Table 3). This is denoted by the differences in the average fold-change between the two sets of isolates for all of the inv (12.4 \pm 0.9 vs. $2.4 \pm 0.3), \operatorname{prg}(4.8 \pm 0.7$ vs. $0.7 \pm 0.5)$, sip (10.5 \pm 1.5 vs. $3.5 \pm 0.7)$, and spa genes (16.0 \pm 


\begin{tabular}{|c|c|c|c|c|c|c|c|c|c|c|c|c|c|c|c|c|c|}
\hline \multirow[b]{2}{*}{ Gene } & \multicolumn{4}{|c|}{ Tetracycline } & \multicolumn{4}{|c|}{ Chloramphenicol } & \multirow[b]{2}{*}{ Gene } & \multicolumn{4}{|c|}{ Tetracycline } & \multicolumn{4}{|c|}{ Chloramphenicol } \\
\hline & 1434 & 5317 & 752 & 530 & 1434 & 5317 & 752 & 530 & & 1434 & 5317 & 752 & 530 & 1434 & 5317 & 752 & 530 \\
\hline avrA & 6.0 & 8.2 & 1.2 & 2.6 & 6.4 & 8.0 & 1.4 & 2.7 & prgK & 7.2 & 5.1 & 1.5 & 2.1 & 5.9 & 7.1 & 1.9 & 2.7 \\
\hline hilA & 13.4 & 14.6 & 1.4 & 4.0 & 11.4 & 9.5 & -1.6 & 2.7 & $\operatorname{sic} P$ & 15.8 & 11.7 & 10.3 & 8.3 & 11.2 & 7.8 & 5.9 & 4.3 \\
\hline hilc & -1.5 & 1.1 & -9.5 & -2.5 & -2.0 & 2.6 & -11.3 & -6.3 & $\operatorname{sip} A$ & 18.3 & 14.4 & 4.2 & 4.7 & 16.6 & 10.8 & 3.2 & 7.3 \\
\hline hild & 6.1 & 5.6 & 1.2 & 3.4 & 5.0 & 5.5 & 1.4 & 2.5 & $\operatorname{sip} B$ & 3.7 & 4.1 & 1.0 & 1.2 & 4.6 & 2.9 & 1.1 & 2.4 \\
\hline $\operatorname{iag} B$ & 20.2 & 17.0 & 3.3 & 6.4 & 16.0 & 7.2 & 1.3 & 11.0 & $\operatorname{sip} C$ & 3.1 & 3.0 & -1.4 & -1.3 & 3.4 & 2.0 & -1.3 & 1.8 \\
\hline invA & 9.4 & 11.2 & 2.7 & 3.5 & 17.3 & 16.3 & 3.0 & 5.0 & $\operatorname{sip} D$ & 17.0 & 16.1 & 4.2 & 4.6 & 25.4 & 12.0 & 4.2 & 9.9 \\
\hline$i n v B$ & 8.1 & 5.9 & 1.0 & 3.2 & 7.3 & 9.6 & 2.0 & 1.7 & $\operatorname{sip} F$ & 9.8 & 17.4 & 4.1 & 5.2 & 15.4 & 9.8 & 3.1 & 8.3 \\
\hline invC & 10.6 & 11.4 & 3.2 & 3.1 & 12.2 & 11.8 & 2.7 & 3.7 & sitA & 2.5 & 2.4 & 2.9 & -1.2 & 2.4 & 1.7 & 1.9 & 4.0 \\
\hline invE & 26.4 & 16.0 & 1.3 & 1.7 & 21.9 & 10.0 & 1.4 & 4.1 & sitB & 1.7 & 2.1 & 2.5 & 1.4 & 2.3 & 1.6 & 1.9 & 2.7 \\
\hline$i n v F$ & 18.9 & 25.5 & 1.6 & 1.7 & 18.1 & 10.3 & -1.0 & 5.3 & sitC & 2.5 & 2.4 & 3.0 & 1.8 & 2.0 & 1.6 & -1.2 & 3.0 \\
\hline invG & 14.5 & 12.3 & 1.1 & 1.4 & 13.7 & 8.1 & -1.2 & 3.1 & sitD & 4.6 & 5.9 & 3.3 & 4.0 & 5.7 & 4.4 & 2.5 & 5.5 \\
\hline invH & 6.7 & 4.8 & -1.3 & 2.6 & 5.1 & 6.7 & 1.1 & 1.3 & spaO & 15.2 & 10.2 & 4.4 & 4.0 & 16.8 & 10.6 & 3.1 & 4.3 \\
\hline invl & 18.1 & 11.0 & 2.7 & 4.9 & 12.1 & 9.3 & 3.1 & 4.8 & spaP & 14.4 & 10.7 & 4.8 & 4.7 & 8.7 & 12.8 & 3.2 & 5.8 \\
\hline invJ & 12.1 & 13.4 & 2.5 & 2.7 & 8.8 & 11.1 & 2.1 & 4.0 & $s p a Q$ & 17.0 & 7.1 & 6.3 & 3.5 & 14.3 & 6.6 & 4.1 & 3.6 \\
\hline $\operatorname{orgAa}$ & 10.4 & 10.2 & 3.5 & 4.6 & 13.5 & 13.4 & 5.3 & 3.7 & spaR & 11.8 & 35.5 & 7.4 & 5.8 & 15.8 & 27.2 & 5.5 & 7.7 \\
\hline $\operatorname{org} A b$ & 2.4 & 1.9 & 1.5 & 1.4 & 1.7 & 1.5 & 2.0 & -1.8 & spas & 26.8 & 32.7 & 16.5 & 9.6 & 42.0 & 25.0 & 14.3 & 15.4 \\
\hline prgH & 5.9 & 6.5 & 1.5 & 2.5 & 9.8 & 8.9 & 1.7 & 3.1 & spat & 6.2 & 6.5 & 1.6 & 1.7 & 6.7 & 4.5 & 1.6 & 3.6 \\
\hline prgl & 3.0 & 2.0 & -2.2 & -1.2 & 1.8 & 2.3 & -1.5 & 1.5 & sprB & 1.9 & 3.1 & -3.7 & -1.2 & 1.8 & 5.5 & -5.6 & -2.1 \\
\hline prgJ & 2.8 & 2.7 & -1.7 & -1.2 & 2.6 & 2.9 & -1.2 & 1.5 & & & & & & & & & \\
\hline
\end{tabular}

FIGURE 5 | RNA-seq analysis of SPI-1 genes. RNA-seq identified the fold-change in expression of SPI-1 genes due to exposure to the antibiotics tetracycline $(16 \mu \mathrm{g} / \mathrm{ml})$ or chloramphenicol $(64 \mu \mathrm{g} / \mathrm{ml})$ when compared to the no-antibiotic control. Numbers in bold are significantly different (FDR-adjusted $P<0.05$ ), while numbers in purple italics are not significant. Green denotes increased gene expression, and red indicates decreased gene expression; the intensity of the color highlights greater change.
2.1 vs. $5.9 \pm 0.8)$. Changes in hilA expression are consistent with the real-time data where 1434, 5317, and 530 had significant differences, but again the average fold-change for 1434 and 5317 was much higher than 530 (12.2 \pm 1.1 vs. $3.3 \pm 0.7$, respectively). Thus, tetracycline and chloramphenicol can increase transcription of SPI-1 genes, but there may be a minimum threshold of induction that is necessary before the invasive phenotype is also induced.

\section{SPI-2}

SPI-2 encodes a TTSS that is required for intracellular replication and survival, and of the 40 genes examined in this functional group, the majority were up-regulated (Figure 6). The bias in upregulation that appeared in SPI-1 for isolates 1434 and 5317 was also present in SPI-2 (Table 3). Several genes encoding effector molecules, such as sifA, $p i p B$, and sseJ, were up-regulated between 6.4 and 51.5-fold for the four isolates exposed to either antibiotic. Only two genes were significantly down-regulated, $t t r R$ and $t t r S$, and these encode a two-component regulatory system for reducing tetrathionate.

\section{SPI-3}

The SPI-3 region has few genes, but these play a role in virulence and intracellular survival in monocytes. Most of the SPI-3 genes were up-regulated (Figure 7), including $m g t B C$. MgtB is used by Salmonella to transport magnesium into the bacterium in magnesium-deficient environments such as an intracellular environment. The tetracycline and chloramphenicol efflux pumps are major facilitator superfamily antiporters that export an antibiotic:proton complex outside of the cell (Chopra and Roberts, 2001; Braibant et al., 2005). It is known that tetracycline molecules bind to magnesium, and the export of this complex would therefore decrease the internal concentration of the ion. It would be beneficial for Salmonella to up-regulate this system in order to continue to export the antibiotic. The $m g t B$ and $m g t C$ genes are up-regulated in isolate 4584 exposed to tetracycline but not chloramphenicol, and these are the only virulence-associated genes examined in this study to be differentially regulated in this isolate.

\section{Attachment}

Salmonella Typhimurium isolates encode up to 13 fimbrial operons (bcf, csg, fim, lpf, pef, saf, stb, stc, std, stf, sth, sti, and stj). These genes, as well as other genes related to attachment, were evaluated (Figure 8). Overall, most of the fimbrial operons were up-regulated in each isolate due to antibiotic exposure. However, there were a few notable differences among the isolates. Most of the pef genes were up-regulated in 530 (DT104) whereas the three DT193 isolates $(1434,5317$, and 752$)$ lacked this operon. Isolates 1434 and 5317 had a greater level of fim gene expression compared to isolates 752 and 530. The fim genes encode the Type I fimbriae, which are important for Salmonella entry into epithelial cells (Ernst et al., 1990; Baumler et al., 1996; Wilson et al., 2000). The increased fim expression in isolates 1434 and 5317 may also play a role in the induced invasion phenotype observed for these two isolates.

Previously, only three fimbrial operons (csg, fim, and pef) had been shown to be expressed in culture, and each requires specific growth conditions (Humphries et al., 2003). Typically, expression of $c s g$ is dependent on growth for over $24 \mathrm{~h}$ on solid medium, while fim expression occurs in the stationary phase for Salmonella grown in liquid medium. The pef genes are encoded on a plasmid and require liquid medium and a low $\mathrm{pH}$ to be expressed in culture. The expression of the remaining fimbrial genes has only been observed in vivo (Nicholson and Baumler, 2001; Humphries et al., 2003). However, in the current study, tetracycline and 


\begin{tabular}{|c|c|c|c|c|c|c|c|c|c|c|c|c|c|c|c|c|c|}
\hline \multirow[b]{2}{*}{ Gene } & \multicolumn{4}{|c|}{ Tetracycline } & \multicolumn{4}{|c|}{ Chloramphenicol } & \multirow[b]{2}{*}{ Gene } & \multicolumn{4}{|c|}{ Tetracycline } & \multicolumn{4}{|c|}{ Chloramphenicol } \\
\hline & 1434 & 5317 & 752 & 530 & 1434 & 5317 & 752 & 530 & & 1434 & 5317 & 752 & 530 & 1434 & 5317 & 752 & 530 \\
\hline pipB & 41.1 & 51.5 & 34.7 & 48.0 & 40.1 & 25.5 & 15.5 & 20.5 & ssaU & 41.0 & 32.7 & 34.8 & 22.6 & 64.2 & 41.1 & 19.3 & 25.4 \\
\hline sifA & 13.0 & 11.8 & 15.0 & 9.4 & 12.0 & 17.7 & 9.4 & 6.4 & ssaV & 11.3 & 15.9 & 9.3 & 7.7 & 16.8 & 10.5 & 4.5 & 5.1 \\
\hline sopD & 2.1 & 1.9 & 1.4 & 2.2 & 2.1 & 2.4 & 1.8 & 2.4 & ssc $A$ & 5.2 & 5.0 & 3.5 & 4.4 & 5.8 & 4.6 & 2.8 & 3.3 \\
\hline sopD2 & 1.8 & 1.6 & 1.5 & 1.2 & 1.7 & 1.4 & -1.1 & -1.0 & $s s c B$ & 15.0 & 9.9 & 5.8 & 7.7 & 10.6 & 6.0 & 3.5 & 3.5 \\
\hline sopE & -1.3 & 1.0 & 1.0 & 1.0 & 1.0 & 1.0 & 1.0 & 1.0 & sseA1 & 7.6 & 8.0 & 4.8 & 7.9 & 8.7 & 4.8 & 2.8 & 3.8 \\
\hline sopE2 & 16.2 & 10.2 & 1.7 & 1.2 & 8.3 & 4.3 & 1.0 & 7.4 & sseB1 & 7.4 & 9.0 & 4.8 & 6.3 & 5.6 & 9.2 & 3.3 & 3.3 \\
\hline$s s a D$ & 10.4 & 24.0 & 16.3 & 12.6 & 19.1 & 20.8 & 7.2 & 7.7 & sseC & 2.7 & 2.8 & 2.3 & 4.0 & 2.7 & 3.1 & 1.6 & 1.3 \\
\hline ssaE & 6.8 & 4.4 & 5.4 & 5.0 & 5.3 & 6.6 & 4.5 & 3.2 & sseD & 3.2 & 3.1 & 3.6 & 5.6 & 6.8 & 4.3 & 3.9 & 1.2 \\
\hline ssaG & 9.1 & 4.8 & 3.4 & 3.3 & 5.6 & 33.1 & -1.4 & 2.4 & sseE & 4.5 & 4.3 & 2.8 & 3.1 & 3.6 & 2.2 & 3.0 & -1.1 \\
\hline ssaH & 11.0 & 10.2 & 7.0 & 24.6 & 22.4 & 12.0 & 3.4 & 2.5 & sseF & 14.4 & 11.9 & 6.8 & 13.5 & 11.5 & 18.6 & 5.6 & 4.7 \\
\hline ssal & 10.3 & 25.0 & 5.5 & 7.1 & 15.2 & 6.1 & 8.4 & 2.2 & sseG & 6.9 & 6.6 & 5.2 & 5.1 & 12.6 & 4.4 & 4.6 & 4.7 \\
\hline ssaJ & 17.1 & 16.5 & 5.9 & 9.5 & 23.4 & 20.6 & 6.2 & 3.9 & ssel & 1.8 & 1.3 & 1.3 & 1.4 & 1.6 & 2.1 & 1.6 & 1.3 \\
\hline ssal & 17.5 & 24.8 & 11.1 & 15.3 & 31.4 & 38.9 & 19.6 & 10.0 & sseJ & 20.0 & 35.4 & 22.3 & 17.1 & 39.2 & 26.7 & 11.9 & 15.4 \\
\hline ssaM & 74.5 & 104.2 & 26.9 & 29.9 & 46.3 & 39.2 & 31.4 & 15.6 & $\mathrm{sspH} 2$ & 2.5 & 2.5 & 2.4 & 2.2 & 2.6 & 2.6 & 2.7 & 2.4 \\
\hline ssaN & 2.8 & 3.1 & 2.8 & 2.7 & 3.1 & 2.7 & 2.0 & 1.6 & $s s r B$ & 8.0 & 9.9 & 6.1 & 7.1 & 6.4 & 6.2 & 3.4 & 5.5 \\
\hline ssaO & 3.0 & 3.9 & 2.2 & 1.8 & 2.3 & 3.3 & 1.7 & -1.1 & $\operatorname{ttr} A$ & 4.7 & 5.1 & 5.2 & 5.1 & 6.1 & 4.0 & 3.8 & 8.8 \\
\hline ssaP & 2.6 & 5.4 & 3.5 & 3.2 & 2.2 & 2.1 & 1.9 & -1.3 & $\operatorname{ttr} B$ & 1.7 & 2.6 & 1.6 & 2.1 & 4.1 & 2.5 & 2.1 & 6.1 \\
\hline ssaQ & 3.6 & 3.3 & 2.8 & 3.1 & 3.8 & 3.1 & 2.0 & 1.6 & $\operatorname{ttrC}$ & 2.9 & 3.5 & 2.6 & 2.5 & 3.1 & 2.4 & 3.0 & 4.0 \\
\hline ssas & 145.7 & 11.0 & 25.2 & 12.0 & 15.2 & 13.6 & 5.1 & 10.0 & ttrR & -5.3 & -3.9 & -5.3 & -6.0 & -3.4 & -2.7 & -5.1 & -3.8 \\
\hline ssat & 18.8 & 14.8 & 11.9 & 6.7 & 17.6 & 11.5 & 14.4 & 8.5 & ttrS & -8.7 & -7.3 & -9.7 & -7.1 & -7.1 & -3.8 & -4.9 & -4.4 \\
\hline
\end{tabular}

FIGURE 6 | RNA-seq analysis of SPI-2 genes. RNA-seq identified the fold-change in expression of SPI-2 genes due to exposure to the antibiotics tetracycline $(16 \mu \mathrm{g} / \mathrm{ml})$ or chloramphenicol $(64 \mu \mathrm{g} / \mathrm{ml})$ when compared to the no-antibiotic control. Numbers in bold are significantly different (FDR-adjusted $P<0.05$ ), while numbers in purple italics are not significant. Green denotes increased gene expression, and red indicates decreased gene expression; the intensity of the color highlights greater change.

\begin{tabular}{|lrrrrrrrrrrr|}
\hline & \multicolumn{4}{c}{ Tetracycline } & \multicolumn{4}{c|}{ Chloramphenicol } \\
Gene & $\mathbf{1 4 3 4}$ & $\mathbf{5 3 1 7}$ & $\mathbf{7 5 2}$ & $\mathbf{5 3 0}$ & $\mathbf{4 5 8 4}$ & $\mathbf{1 4 3 4}$ & $\mathbf{5 3 1 7}$ & $\mathbf{7 5 2}$ & $\mathbf{5 3 0}$ & $\mathbf{4 5 8 4}$ \\
\hline cigR & $\mathbf{4 . 5}$ & $\mathbf{5 . 3}$ & $\mathbf{2 . 5}$ & $\mathbf{3 . 2}$ & 1.9 & $\mathbf{5 . 5}$ & $\mathbf{3 . 4}$ & $\mathbf{1 . 8}$ & $\mathbf{2 . 2}$ & -1.0 \\
mart & $\mathbf{1 6 . 1}$ & $\mathbf{1 4 . 1}$ & $\mathbf{8 . 6}$ & $\mathbf{8 . 0}$ & 5.1 & $\mathbf{1 4 . 7}$ & $\mathbf{1 3 . 1}$ & $\mathbf{9 . 7}$ & $\mathbf{7 . 7}$ & 1.1 \\
mgtB & $\mathbf{1 6 . 2}$ & $\mathbf{2 1 . 0}$ & $\mathbf{2 6 . 0}$ & $\mathbf{5 8 . 0}$ & $\mathbf{1 8 . 4}$ & $\mathbf{1 6 . 2}$ & $\mathbf{1 6 . 9}$ & $\mathbf{2 3 . 9}$ & $\mathbf{2 3 . 6}$ & 1.3 \\
mgtC & 117.9 & $\mathbf{9 8 . 1}$ & $\mathbf{8 7 . 9}$ & $\mathbf{2 0 1 . 0}$ & $\mathbf{5 0 . 5}$ & $\mathbf{1 0 7 . 1}$ & $\mathbf{1 2 4 . 1}$ & $\mathbf{1 7 4 . 4}$ & $\mathbf{1 2 4 . 3}$ & 1.1 \\
misL & $\mathbf{2 . 1}$ & $\mathbf{2 . 1}$ & $\mathbf{2 . 2}$ & $\mathbf{2 . 2}$ & 1.7 & $\mathbf{2 . 6}$ & $\mathbf{2 . 5}$ & $\mathbf{2 . 5}$ & $\mathbf{2 . 4}$ & -1.0 \\
rmbA & $\mathbf{6 . 2}$ & $\mathbf{5 . 9}$ & $\mathbf{6 . 6}$ & $\mathbf{4 . 7}$ & 2.0 & $\mathbf{8 . 0}$ & 2.5 & 2.4 & $\mathbf{6 . 2}$ & 3.0 \\
slsA & $\mathbf{6 . 1}$ & $\mathbf{7 . 0}$ & -1.2 & $\mathbf{1 . 6}$ & 1.0 & $\mathbf{5 . 6}$ & $\mathbf{4 . 1}$ & $\mathbf{- 1 . 9}$ & -1.1 & 1.1 \\
\hline
\end{tabular}

FIGURE 7 | RNA-seq analysis of SPI-3 genes. RNA-seq identified the fold-change in expression of SPI-3 genes due to exposure to the antibiotics tetracycline $(16 \mu \mathrm{g} / \mathrm{ml})$ or chloramphenicol $(64 \mu \mathrm{g} / \mathrm{ml})$ when compared to the no-antibiotic control. Numbers in bold are significantly different

(FDR-adjusted $P<0.05$ ), while numbers in purple italics are not significant. Green denotes increased gene expression, and red indicates decreased gene expression; the intensity of the color highlights greater change.

chloramphenicol induced the expression of genes in up to 11 different fimbrial operons in isolates 1434, 5317, 752, and 530. Also, the fimbrial genes in the $b c f, l p f, s t b, s t c, s t d$, and $s t h$ operons have been shown to be associated with persistence in mice (Weening et al., 2005); as all six of these operons can be induced by the two antibiotics, this could be one factor that contributes to the increased morbidity observed in MDR Salmonella patients that have been treated with antibiotics (Molbak, 2005).

\section{ELECTRON MICROSCOPY DEMONSTRATES DECREASED FLAGELLA AND INCREASED AGGLUTINATION DUE TO ANTIBIOTIC EXPOSURE}

Electron microscopy was used to visualize isolate 1434 in early-log phase treated with $64 \mu \mathrm{g} / \mathrm{ml}$ chloramphenicol compared to a no antibiotic control (Figure 9). Salmonella that were not exposed to chloramphenicol (control) had many flagella (Figure 9A) and were dispersed (Figure 9B). The chloramphenicol-treated Salmonella had few-to-no flagella (Figure 9C) and had increased bacterial agglutination compared to the untreated sample (Figure 9D). These figures are representative of other regions of the samples that were also visualized. Isolate 1434 exposed to $16 \mu \mathrm{g} / \mathrm{ml}$ tetracycline had the same result (data not shown). The decreased flagella and increased agglutination are consistent with the RNA-seq data that demonstrates decreased motility and increased attachment gene expression.

\section{CONCLUDING REMARKS}

Tetracyclines are approved for growth promotion and therapeutic use in swine, cattle, and poultry in the U.S.; it was reported that over 4.6 million $\mathrm{kg}$ of tetracyclines were sold for use in livestock in a single year (USGAO, 2011). While tetracycline usage may directly select for resistant Salmonella encoding tet genes, it may also indirectly select for other resistance genes (such as floR) and virulence factors that are encoded on the same plasmid. For example, Hradecka et al. reported the Salmonella virulence plasmid can recombine with an antibiotic resistance plasmid, ensuring that the plasmid and its content can be selected based on either virulence or antibiotics (Hradecka et al., 2008). Because of the widespread use of antibiotics in humans and livestock, it is important to understand the effects these antibiotics have on MDR Salmonella.

Tetracycline and chloramphenicol exposure of MDR Salmonella in our transcriptomic data indicate that the regulation of the invasive phenotype in Salmonella, which normally takes over $8 \mathrm{~h}$ to induce, can be accelerated to occur in $30 \mathrm{~min}$. While gene expression data cannot assess protein levels or posttranscriptional interactions of each individual gene that have an impact on the invasion phenotype, the data suggests there is a 


\begin{tabular}{|c|c|c|c|c|c|c|c|c|c|c|c|c|c|c|c|c|c|}
\hline \multirow[b]{2}{*}{ Gene } & \multicolumn{4}{|c|}{ Tetracycline } & \multicolumn{4}{|c|}{ Chloramphenicol } & \multirow[b]{2}{*}{ Gene } & \multicolumn{4}{|c|}{ Tetracycline } & \multicolumn{4}{|c|}{ Chloramphenicol } \\
\hline & 1434 & 5317 & 752 & 530 & 1434 & 5317 & 752 & 530 & & 1434 & 5317 & 752 & 530 & 1434 & 5317 & 752 & 530 \\
\hline$b c f A$ & 5.2 & 5.0 & 2.7 & 3.2 & 4.6 & 4.8 & 3.2 & 4.2 & safC & 1.3 & 1.7 & 1.6 & 1.6 & 1.8 & 1.9 & 1.5 & 1.8 \\
\hline$b c f B$ & 3.3 & 5.2 & 4.0 & 4.4 & 6.8 & 7.3 & 3.0 & 4.3 & safD & 3.6 & 3.8 & 3.9 & 4.2 & 3.9 & 4.7 & 3.2 & 2.4 \\
\hline$b c f C$ & 4.0 & 3.9 & 3.2 & 3.5 & 4.6 & 3.6 & 2.8 & 4.0 & shdA & 2.9 & 3.3 & 3.0 & 2.9 & 3.8 & 3.8 & 3.2 & 3.5 \\
\hline$b c f D$ & 2.2 & 1.8 & 1.5 & 1.5 & 2.9 & 2.1 & 1.9 & 1.5 & $\sin H$ & 9.2 & 10.6 & 8.8 & 8.3 & 11.7 & 9.1 & 9.3 & 11.1 \\
\hline$b c f E$ & 4.1 & 5.6 & 4.5 & 1.5 & 6.3 & 3.1 & 3.5 & 4.1 & stbA & 11.0 & 9.1 & 29.3 & 21.9 & 14.0 & 10.7 & 15.4 & 23.1 \\
\hline$b c f F$ & 1.6 & 1.6 & 1.2 & 1.1 & 2.6 & 1.7 & 1.5 & 2.8 & $s t b B$ & 18.5 & 37.2 & 27.5 & 20.4 & 23.1 & 39.7 & 39.0 & 76.0 \\
\hline$b c f G$ & 2.4 & 1.9 & 1.7 & 1.6 & 2.3 & 2.8 & 2.5 & 2.3 & stb C & 6.9 & 7.1 & 6.1 & 4.8 & 8.1 & 6.4 & 6.8 & 7.6 \\
\hline $\operatorname{csg} A$ & 13.6 & 16.3 & 8.2 & 6.1 & 24.9 & 15.9 & 8.2 & 15.8 & $s t b D$ & 7.6 & 7.7 & 6.4 & 5.3 & 8.4 & 8.7 & 6.1 & 7.3 \\
\hline $\operatorname{csg} B$ & 116.6 & 124.9 & 38.8 & 20.4 & 39.2 & 40.3 & 36.2 & 35.6 & $s t b E$ & 7.0 & 6.6 & 6.1 & 5.9 & 8.3 & 7.2 & 3.9 & 5.4 \\
\hline $\operatorname{csg} D$ & 10.7 & 10.6 & 12.6 & 9.6 & 16.2 & 7.0 & 7.3 & 7.7 & stc $A$ & 2.3 & 2.8 & 4.5 & -2.0 & 5.5 & 2.8 & 1.4 & 1.1 \\
\hline $\operatorname{csg} E$ & 11.9 & 19.3 & 19.4 & 8.7 & 12.3 & 19.1 & 4.8 & 7.3 & stc $B$ & 58.6 & 38.7 & 60.5 & 4.7 & 55.8 & 18.6 & 19.0 & 17.0 \\
\hline $\operatorname{csg} F$ & 8.5 & 7.3 & 24.3 & 5.9 & 6.2 & 6.9 & 5.2 & 5.3 & stc C & 25.5 & 29.1 & 25.6 & 12.5 & 48.5 & 22.2 & 17.4 & 22.9 \\
\hline $\operatorname{csg} G$ & 5.6 & 6.3 & 5.7 & 3.4 & 5.8 & 7.0 & 3.5 & 4.6 & stcD & 42.0 & 40.6 & 23.9 & 13.1 & 34.3 & 18.9 & 9.1 & 24.4 \\
\hline fimA & 4.1 & 5.2 & -11.4 & -7.8 & 7.3 & 7.9 & -6.1 & -1.6 & std $A$ & 1.5 & 1.7 & 2.5 & 2.8 & 1.6 & 2.3 & 1.6 & 2.9 \\
\hline fimB & 3.8 & 4.3 & 3.9 & 5.0 & 4.8 & 4.8 & 5.4 & 5.5 & $s t d B$ & 2.5 & 3.4 & 4.1 & 2.6 & 3.1 & 3.7 & 4.3 & 4.9 \\
\hline $\operatorname{fim} C$ & 6.7 & 8.8 & -2.7 & -2.8 & 13.1 & 9.0 & -2.6 & 1.8 & $s t d C$ & 16.1 & 16.4 & 23.9 & 19.6 & 22.6 & 18.9 & 10.7 & 27.9 \\
\hline fimD & 2.7 & 2.7 & -1.1 & 1.2 & 4.2 & 3.6 & -1.4 & 2.6 & $s t d D$ & 17.6 & 8.6 & 10.7 & 11.8 & 13.6 & 11.6 & 8.4 & 12.2 \\
\hline fimF & 6.7 & 6.1 & 2.0 & 2.0 & 7.5 & 7.6 & 1.7 & 6.0 & $s t d E$ & 15.8 & 15.4 & 11.4 & 15.0 & 14.8 & 15.9 & 11.1 & 21.8 \\
\hline $\mathrm{fimH}$ & 2.1 & 2.9 & -1.1 & 1.8 & 3.5 & 5.0 & -1.3 & 2.2 & $s t d F$ & 4.7 & 4.7 & 4.8 & 5.6 & 5.1 & 4.7 & 4.0 & 6.4 \\
\hline fiml & 10.4 & 6.0 & -1.4 & -1.0 & 9.1 & 12.8 & -1.5 & 3.9 & stfA & 3.4 & 3.3 & 3.8 & 1.8 & 3.5 & 3.0 & 2.5 & 3.3 \\
\hline fimW & 16.0 & 8.5 & 4.2 & 4.8 & 8.1 & 6.2 & 1.6 & 4.8 & stfC & 7.5 & 10.1 & 8.1 & 7.6 & 12.3 & 7.9 & 5.8 & 8.9 \\
\hline fim $Y$ & 9.2 & 18.2 & 5.1 & 5.2 & 16.5 & 9.4 & 2.5 & 7.7 & stfD & 1.4 & 1.5 & 1.6 & 1.7 & 2.5 & 2.1 & 2.5 & 1.7 \\
\hline fimZ & 11.6 & 6.9 & -1.4 & -1.1 & 12.3 & 4.0 & -3.2 & 3.8 & stfE & 3.5 & 2.3 & 12.2 & 3.9 & 5.5 & 3.3 & 6.6 & 2.8 \\
\hline IpfA & 5.5 & 4.7 & 2.8 & 5.2 & 7.2 & 4.9 & 3.7 & 4.8 & stfF & -1.2 & -1.1 & 1.3 & 1.1 & 1.0 & 1.2 & 1.3 & 1.0 \\
\hline IpfB & 7.1 & 9.4 & 8.4 & 3.0 & 15.8 & 9.3 & 7.7 & 9.1 & stfG & 3.9 & 4.0 & 3.2 & 3.8 & 2.5 & 1.9 & 3.2 & 1.9 \\
\hline IpfC & 2.9 & 3.1 & 2.8 & 2.8 & 3.9 & 3.8 & 3.8 & 3.5 & sthA & 17.1 & 16.2 & 15.4 & 7.7 & 18.7 & 10.4 & 11.7 & 9.1 \\
\hline IpfE & 2.5 & 4.3 & 2.0 & 2.1 & 4.2 & 2.8 & 2.4 & 2.7 & sthB & 23.2 & 17.2 & 12.9 & 16.2 & 21.4 & 16.2 & 21.6 & 7.6 \\
\hline pefA & --- & --- & --- & 1.3 & --- & --- & --- & 1.9 & sthD & 5.8 & 6.3 & 5.5 & 2.7 & 8.7 & 5.7 & 5.6 & 3.3 \\
\hline pefB & --- & --- & --- & 28.5 & --- & --- & -- & 30.4 & stiA & 1.2 & 1.4 & -1.1 & 1.2 & 2.0 & 1.5 & 1.6 & 2.7 \\
\hline pefC & --- & --- & --- & 3.1 & --- & --- & --- & 2.5 & stiB & 3.6 & 3.8 & 2.3 & 2.6 & 7.5 & 7.4 & 6.7 & 3.7 \\
\hline pefD & --- & --- & --- & 2.0 & --- & --- & --- & 2.0 & stic & 4.4 & 4.5 & 3.0 & 2.2 & 5.1 & 3.5 & 3.4 & 3.9 \\
\hline pefl & --- & --- & --- & 10.3 & --- & --- & --- & 7.3 & stiH & 2.1 & 2.7 & 2.0 & 1.9 & 2.7 & 2.9 & 2.2 & 2.3 \\
\hline ratB & 2.3 & 2.5 & 2.0 & 1.8 & 2.7 & 2.7 & 1.8 & 2.1 & stjA & 1.2 & 1.4 & 1.1 & 1.5 & 1.9 & 1.8 & 1.1 & 1.5 \\
\hline safA & 15.9 & 13.6 & 19.9 & 4.1 & 20.5 & 9.2 & 11.6 & 6.7 & $s t j B$ & 4.0 & 4.7 & 3.7 & 3.6 & 6.3 & 5.2 & 4.3 & 4.7 \\
\hline safB & 7.9 & 10.8 & 7.9 & 7.2 & 11.6 & 6.3 & 7.3 & 5.2 & stjC & 32.7 & 24.5 & 12.5 & 9.7 & 59.9 & 39.0 & 16.1 & 12.6 \\
\hline
\end{tabular}

FIGURE 8 | RNA-seq analysis of genes associated with attachment. RNA-seq identified the fold-change in expression of genes associated with attachment due to exposure to the antibiotics tetracycline $(16 \mu \mathrm{g} / \mathrm{ml})$ or chloramphenicol $(64 \mu \mathrm{g} / \mathrm{ml})$ when compared to the no-antibiotic control.
Numbers in bold are significantly different (FDR-adjusted $P<0.05$ ), while numbers in purple italics are not significant. Green denotes increased gene expression, and red indicates decreased gene expression; the intensity of the color highlights greater change. coordinated regulation of the regulons involved in attachment, motility, and invasion due to chloramphenicol and tetracycline. Furthermore, the attachment regulon appears to extend beyond the fim operon to include other fimbrial operons that would not normally be expressed in culture. Chloramphenicol and tetracycline may be acting on a complex stimulon with multiple interacting regulons in a system that is currently uncharacterized in culture.

The induced invasion phenotype observed may be directly activated by the antibiotic response pathway that is stimulated to express the efflux pump after antibiotic exposure. It may also be an indirect response due to the changes in the cellular environment due to the presence of the antibiotic and potential changes in $\mathrm{H}^{+}$and $\mathrm{Mg}^{2+}$ concentrations (Yamaguchi et al., 1990). For instance, the response may be due to the "tetracycline transport cycle" in resistant cells where extracellular tetracycline is protonated and diffuses into the bacterial cell in a neutral form. Once inside the cell, the tetracycline is predicted to dissociate from the proton due the higher intracellular $\mathrm{pH}$. The intracellular concentration of $\mathrm{Mg}$ may facilitate the formation of a tetracycline-Mg chelate complex that can then be exported by the TetA antiporter with the simultaneous import of a proton. In this model, the export of tetracycline is electrically neutral $\left(\mathrm{Mg}^{+}\right.$exported while $\mathrm{H}^{+}$imported) but there is a net gain of one proton from the initial diffusion of tetracycline into the bacterial cell. Therefore, the internal $\mathrm{pH}$ of the bacteria may shift due to the accumulation of protons with the decreased $\mathrm{pH}$ conditions triggering a secondary response that activates the invasion genes. Interestingly, $m g t B C$ present in SPI-3 is up-regulated by both tetracycline and chloramphenicol exposure. The MgtC protein inhibits the bacterium's own $\mathrm{F}_{1} \mathrm{~F}_{0}$ ATP synthase that couples proton translocation across the bacterial membrane with ATP synthesis/hydrolysis (Lee et al., 2013). The intracellular $\mathrm{pH}$ is lower and ATP levels higher for an $m g t C$ mutant compared to wild-type $S$. Typhimurium suggesting that intracellular $\mathrm{pH}$ or ATP/ADP levels could influence the gene expression seen in our investigation. Because the induced invasion phenotype does not occur in all the MDR isolates tested, there is likely a genetic component 


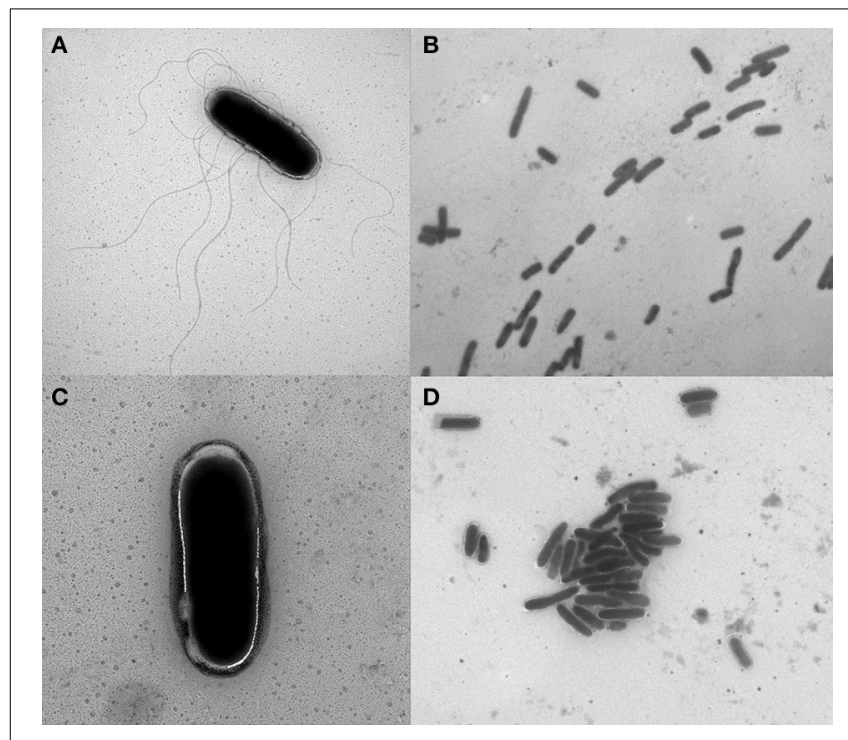

FIGURE 9 | Electron micrographs of Salmonella with and without chloramphenicol exposure. S. Typhimurium isolate 1434 grown to early-log phase $\left(\mathrm{OD}_{600}=0.15\right)$ and exposed to $(\mathbf{A}, \mathbf{B}) 0 \mu \mathrm{g} / \mathrm{ml}$ or $(\mathbf{C}, \mathbf{D})$ $64 \mu \mathrm{g} / \mathrm{ml}$ chloramphenicol for $30 \mathrm{~min}$. Isolates exposed to chloramphenicol had fewer flagella and increased bacterial agglutination compared to the control (no antibiotic) condition. These figures are representative of other regions of the samples that were also visualized.

that is involved. Additional investigations using genomics and proteomics will provide greater insights into the effect antibiotics have on these MDR Salmonella isolates.

\section{ACKNOWLEDGMENTS}

We would like to thank Briony Atkinson for her outstanding technical assistance, as well as Judith Stasko for her fantastic electron microscopy work. We would also like to thank Dr. Tracy Nicholson and Dr. Thomas Casey for their critical review of the manuscript. This research was supported by USDA, ARS CRIS funds. Mention of trade names or commercial products in this article is solely for the purpose of providing specific information and does not imply recommendations or endorsement by the US Department of Agriculture. USDA is an equal opportunity provider and employer.

\section{REFERENCES}

Baumler, A. J., Tsolis, R. M., and Heffron, F. (1996). Contribution of fimbrial operons to attachment to and invasion of epithelial cell lines by Salmonella typhimurium. Infect. Immun. 64, 1862-1865.

Blickwede, M., Goethe, R., Wolz, C., Valentin-Weigand, P., and Schwarz, S. (2005). Molecular basis of florfenicol-induced increase in adherence of Staphylococcus aureus strain Newman. J. Antimicrob. Chemother. 56, 315-323. doi: $10.1093 /$ jac/dki233

Boyd, D., Peters, G. A., Cloeckaert, A., Boumedine, K. S., Chaslus-Dancla, E., Imberechts, H., et al. (2001). Complete nucleotide sequence of a 43kilobase genomic island associated with the multidrug resistance region of Salmonella enterica serovar Typhimurium DT104 and its identification in phage type DT120 and serovar Agona. J. Bacteriol. 183, 5725-5732. doi: 10.1128/JB.183.19.5725-5732.2001

Braibant, M., Chevalier, J., Chaslus-Dancla, E., Pages, J. M., and Cloeckaert, A. (2005). Structural and functional study of the phenicol-specific efflux pump FloR belonging to the major facilitator superfamily. Antimicrob. Agents Chemother. 49, 2965-2971. doi: 10.1128/AAC.49.7.2965-2971.2005

Brunelle, B. W., Bearson, S. M., and Bearson, B. L. (2013). Tetracycline accelerates the temporally-regulated invasion response in specific isolates of multidrugresistant Salmonella enterica serovar Typhimurium. BMC Microbiol. 13:202. doi: 10.1186/1471-2180-13-202

Brunelle, B. W., Bearson, S. M. D., and Bearson, B. L. (2011). Salmonella enterica serovar Typhimurium DT104 invasion is not enhanced by sub-inhibitory concentrations of the antibiotic florfenicol. Vet. Sci. Technol. 2:104. doi: 10.4172/2157-7579.1000104

Carlson, S. A., Browning, M., Ferris, K. E., and Jones, B. D. (2000) Identification of diminished tissue culture invasiveness among multiple antibiotic resistant Salmonella typhimurium DT104. Microb. Pathog. 28, 37-44. doi: 10.1006/mpat.1999.0322

CDC. (2012). National Antimicrobial Resistance Monitoring System for Enteric Bacteria (NARMS): Human Isolates Final Report, 2010. Atlanta: U.S. Department of Health and Human Services, CDC.

Chang, H. R., Loo, L. H., Jeyaseelan, K., Earnest, L., and Stackebrandt, E. (1997). Phylogenetic relationships of Salmonella typhi and Salmonella typhimurium based on 16S rRNA sequence analysis. Int. J. Syst. Bacteriol. 47, 1253-1254. doi: 10.1099/00207713-47-4-1253

Chilcott, G. S., and Hughes, K. T. (2000). Coupling of flagellar gene expression to flagellar assembly in Salmonella enterica serovar Typhimurium and Escherichia coli. Microbiol. Mol. Biol. Rev. 64, 694-708. doi: 10.1128/MMBR.64.4.694708.2000

Chopra, I., and Roberts, M. (2001). Tetracycline antibiotics: mode of action, applications, molecular biology, and epidemiology of bacterial resistance. Microbiol. Mol. Biol. Rev. 65, 232-260. doi: 10.1128/MMBR.65.2.232-260.2001

Deneve, C., Bouttier, S., Dupuy, B., Barbut, F., Collignon, A., and Janoir, C. (2009). Effects of subinhibitory concentrations of antibiotics on colonization factor expression by moxifloxacin-susceptible and moxifloxacin-resistant Clostridium difficile strains. Antimicrob. Agents Chemother. 53, 5155-5162. doi: 10.1128/AAC.00532-09

Doane, F. W., and Anderson, N. (1987). Electron Microscopy in Diagnostic Virology: a Practical Guide and Atlas. Cambridge, UK: Cambridge University Press.

Eckert, C., Gautier, V., Saladin-Allard, M., Hidri, N., Verdet, C., Ould-Hocine, Z., et al. (2004). Dissemination of CTX-M-type beta-lactamases among clinical isolates of Enterobacteriaceae in Paris, France. Antimicrob. Agents Chemother. 48, 1249-1255. doi: 10.1128/AAC.48.4.1249-1255.2004

Economic Research Service. (2009). Foodborne Illness Cost Calculator: Salmonella. Washington, DC: United States Department of Agriculture.

Elsinghorst, E. A. (1994). Measurement of invasion by gentamicin resistance. Meth. Enzymol. 236, 405-420. doi: 10.1016/0076-6879(94)36030-8

Ernst, R. K., Dombroski, D. M., and Merrick, J. M. (1990). Anaerobiosis, type 1 fimbriae, and growth phase are factors that affect invasion of HEp-2 cells by Salmonella typhimurium. Infect. Immun. 58, 2014-2016.

Fabrega, A., and Vila, J. (2013). Salmonella enterica serovar Typhimurium skills to succeed in the host: virulence and regulation. Clin. Microbiol. Rev. 26, 308-341. doi: 10.1128/CMR.00066-12

Goh, E. B., Yim, G., Tsui, W., McClure, J., Surette, M. G., and Davies, J. (2002). Transcriptional modulation of bacterial gene expression by subinhibitory concentrations of antibiotics. Proc. Natl. Acad. Sci. U.S.A. 99, 17025-17030. doi: $10.1073 /$ pnas.252607699

Golding, G. R., Olson, A. B., Doublet, B., Cloeckaert, A., Christianson, S., Graham, M. R., et al. (2007). The effect of the Salmonella genomic island 1 on in vitro global gene expression in Salmonella enterica serovar Typhimurium LT2. Microbes Infect. 9, 21-27. doi: 10.1016/j.micinf.2006.10.004

Hradecka, H., Karasova, D., and Rychlik, I. (2008). Characterization of Salmonella enterica serovar Typhimurium conjugative plasmids transferring resistance to antibiotics and their interaction with the virulence plasmid. J. Antimicrob. Chemother. 62, 938-941. doi: 10.1093/jac/dkn286

Humphries, A. D., Raffatellu, M., Winter, S., Weening, E. H., Kingsley, R. A., Droleskey, R., et al. (2003). The use of flow cytometry to detect expression of subunits encoded by 11 Salmonella enterica serotype Typhimurium fimbrial operons. Mol. Microbiol. 48, 1357-1376. doi: 10.1046/j.1365-2958.2003.03507.x

Ibarra, J. A., Knodler, L. A., Sturdevant, D. E., Virtaneva, K., Carmody, A. B., Fischer, E. R., et al. (2010). Induction of Salmonella pathogenicity island 1 under different growth conditions can affect Salmonella-host cell interactions in vitro. Microbiology 156, 1120-1133. doi: 10.1099/mic.0.032896-0 
Kuhle, V., and Hensel, M. (2004). Cellular microbiology of intracellular Salmonella enterica: functions of the type III secretion system encoded by Salmonella pathogenicity island 2. Cell. Mol. Life Sci. 61, 2812-2826. doi: 10.1007/s00018004-4248-z

Kuroda, H., Kuroda, M., Cui, L., and Hiramatsu, K. (2007). Subinhibitory concentrations of beta-lactam induce haemolytic activity in Staphylococcus aureus through the SaeRS two-component system. FEMS Microbiol. Lett. 268, 98-105. doi: 10.1111/j.1574-6968.2006.00568.x

Lee, C. A., Jones, B. D., and Falkow, S. (1992). Identification of a Salmonella typhimurium invasion locus by selection for hyperinvasive mutants. Proc. Natl. Acad. Sci. U.S.A. 89, 1847-1851. doi: 10.1073/pnas.89.5.1847

Lee, E. J., Pontes, M. H., and Groisman, E. A. (2013). A bacterial virulence protein promotes pathogenicity by inhibiting the bacterium's own F1Fo ATP synthase. Cell 154, 146-156. doi: 10.1016/j.cell.2013.06.004

Linares, J. F., Gustafsson, I., Baquero, F., and Martinez, J. L. (2006). Antibiotics as intermicrobial signaling agents instead of weapons. Proc. Natl. Acad. Sci. U.S.A. 103, 19484-19489. doi: 10.1073/pnas.0608949103

Lostroh, C. P., and Lee, C. A. (2001). The Salmonella pathogenicity island-1 type III secretion system. Microbes Infect. 3, 1281-1291. doi: 10.1016/S12864579(01)01488-5

McClelland, M., Sanderson, K. E., Spieth, J., Clifton, S. W., Latreille, P., Courtney, L., et al. (2001). Complete genome sequence of Salmonella enterica serovar Typhimurium LT2. Nature 413, 852-856. doi: 10.1038/35101614

Mitani, M., and Iino, T. (1968). Electron microscopy of Salmonella flagella in methylcellulose solution. J. Gen. Microbiol. 50, 459-464. doi: 10.1099/0022128750-3-459

Molbak, K. (2005). Human health consequences of antimicrobial drug-resistant Salmonella and other foodborne pathogens. Clin. Infect. Dis. 41, 1613-1620. doi: 10.1086/497599

Morita, Y., Tomida, J., and Kawamura, Y. (2014). Responses of Pseudomonas aeruginosa to antimicrobials. Front. Microbiol. 4:422. doi: 10.3389/fmicb.2013.00422

Nicholson, T. L., and Baumler, A. J. (2001). Salmonella enterica serotype typhimurium elicits cross-immunity against a Salmonella enterica serotype enteritidis strain expressing LP fimbriae from the lac promoter. Infect. Immun. 69, 204-212. doi: 10.1128/IAI.69.1.204-212.2001

Pfaffl, M. W. (2001). A new mathematical model for relative quantification in realtime RT-PCR. Nucleic Acids Res. 29:e45. doi: 10.1093/nar/29.9.e45

Ramakers, C., Ruijter, J. M., Deprez, R. H., and Moorman, A. F. (2003). Assumption-free analysis of quantitative real-time polymerase chain reaction (PCR) data. Neurosci. Lett. 339, 62-66. doi: 10.1016/S0304-3940(02) 01423-4

Robinson, M. D., McCarthy, D. J., and Smyth, G. K. (2010). edgeR: a Bioconductor package for differential expression analysis of digital gene expression data. Bioinformatics 26, 139-140. doi: 10.1093/bioinformatics/btp616

Saini, S., Slauch, J. M., Aldridge, P. D., and Rao, C. V. (2010). Role of cross talk in regulating the dynamic expression of the flagellar Salmonella pathogenicity island 1 and type 1 fimbrial genes. J. Bacteriol. 192, 5767-5777. doi: 10.1128/JB.00624-10

Scallan, E., Griffin, P. M., Angulo, F. J., Tauxe, R. V., and Hoekstra, R. M. (2011). Foodborne illness acquired in the United States-unspecified agents. Emerging Infect. Dis. 17, 16-22. doi: 10.3201/eid1701.091101p2
Schwarz, S., Kehrenberg, C., Doublet, B., and Cloeckaert, A. (2004). Molecular basis of bacterial resistance to chloramphenicol and florfenicol. FEMS Microbiol. Rev. 28, 519-542. doi: 10.1016/j.femsre.2004.04.001

Shen, L., Shi, Y., Zhang, D., Wei, J., Surette, M. G., and Duan, K. (2008). Modulation of secreted virulence factor genes by subinhibitory concentrations of antibiotics in Pseudomonas aeruginosa. J. Microbiol. 46, 441-447. doi: 10.1007/s12275-0080054-X

USGAO. (2011). Agencies Have Made Limited Progress Addressing Antibiotic Use in Animals. US Government Accountability Office. Available online at: http:// www.gao.gov/products/GAO-11--801

Varma, J. K., Greene, K. D., Ovitt, J., Barrett, T. J., Medalla, F., and Angulo, F. J. (2005). Hospitalization and antimicrobial resistance in Salmonella outbreaks, 1984-2002. Emerging Infect. Dis. 11, 943-946. doi: 10.3201/eid1106.041231

Weening, E. H., Barker, J. D., Laarakker, M. C., Humphries, A. D., Tsolis, R. M., and Baumler, A. J. (2005). The Salmonella enterica serotype Typhimurium $l p f$, $b c f, s t b, s t c, s t d$, and $s t h$ fimbrial operons are required for intestinal persistence in mice. Infect. Immun. 73, 3358-3366. doi: 10.1128/IAI.73.6.3358-3366.2005

Weill, F. X., Guesnier, F., Guibert, V., Timinouni, M., Demartin, M., Polomack, L., et al. (2006). Multidrug resistance in Salmonella enterica serotype Typhimurium from humans in France (1993 to 2003). J. Clin. Microbiol. 44, 700-708. doi: 10.1128/JCM.44.3.700-708.2006

Weir, E. K., Martin, L. C., Poppe, C., Coombes, B. K., and Boerlin, P. (2008). Subinhibitory concentrations of tetracycline affect virulence gene expression in a multi-resistant Salmonella enterica subsp. enterica serovar Typhimurium DT104. Microbes Infect. 10, 901-907. doi: 10.1016/j.micinf.2008.05.005

Wilson, R. L., Elthon, J., Clegg, S., and Jones, B. D. (2000). Salmonella enterica serovars gallinarum and pullorum expressing Salmonella enterica serovar typhimurium type 1 fimbriae exhibit increased invasiveness for mammalian cells. Infect. Immun. 68, 4782-4785. doi: 10.1128/IAI.68.8.4782-4785.2000

Yamaguchi, A., Udagawa, T., and Sawai, T. (1990). Transport of divalent cations with tetracycline as mediated by the transposon Tn10-encoded tetracycline resistance protein. J. Biol. Chem. 265, 4809-4813.

Conflict of Interest Statement: The authors declare that the research was conducted in the absence of any commercial or financial relationships that could be construed as a potential conflict of interest.

Received: 15 September 2014; accepted: 28 December 2014; published online: 30 January 2015.

Citation: Brunelle BW, Bearson BL and Bearson SMD (2015) Chloramphenicol and tetracycline decrease motility and increase invasion and attachment gene expression in specific isolates of multidrug-resistant Salmonella enterica serovar Typhimurium. Front. Microbiol. 5:801. doi: 10.3389/fmicb.2014.00801

This article was submitted to Antimicrobials, Resistance and Chemotherapy, a section of the journal Frontiers in Microbiology.

Copyright (C) 2015 Brunelle, Bearson and Bearson. This is an open-access article distributed under the terms of the Creative Commons Attribution License (CC BY). The use, distribution or reproduction in other forums is permitted, provided the original author(s) or licensor are credited and that the original publication in this journal is cited, in accordance with accepted academic practice. No use, distribution or reproduction is permitted which does not comply with these terms. 